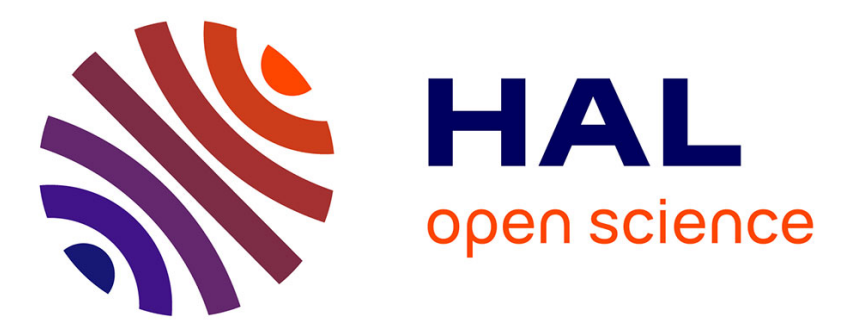

\title{
Activation of the brain-pituitary-gonadotropic axis in the black porgy Acanthopagrus schlegelii during gonadal differentiation and testis development and effect of estradiol treatment
}

Chien-Ju Lin, Guan-Chung Wu, Sylvie Dufour, Ching-Fong Chang

\section{To cite this version:}

Chien-Ju Lin, Guan-Chung Wu, Sylvie Dufour, Ching-Fong Chang. Activation of the brain-pituitarygonadotropic axis in the black porgy Acanthopagrus schlegelii during gonadal differentiation and testis development and effect of estradiol treatment. General and Comparative Endocrinology, 2019, 281, pp.17-29. 10.1016/j.ygcen.2019.05.008 . hal-02407207

\section{HAL Id: hal-02407207 \\ https://hal.science/hal-02407207}

Submitted on 25 Oct 2021

HAL is a multi-disciplinary open access archive for the deposit and dissemination of scientific research documents, whether they are published or not. The documents may come from teaching and research institutions in France or abroad, or from public or private research centers.
L'archive ouverte pluridisciplinaire HAL, est destinée au dépôt et à la diffusion de documents scientifiques de niveau recherche, publiés ou non, émanant des établissements d'enseignement et de recherche français ou étrangers, des laboratoires publics ou privés.

\section{(ㄷ)(1) $\$$}

Distributed under a Creative Commons Attribution - NonCommerciall 4.0 International 
1 Activation of the brain-pituitary-gonadotropic axis in the black porgy Acanthopagrus 2 schlegelii during gonadal differentiation and testis development and effect of estradiol 3 treatment

4

5 Chien-Ju Lin ${ }^{1,2}$, Guan-Chung $\mathrm{Wu}^{1,2}$, Sylvie Dufour ${ }^{3 *}$, and Ching-Fong Chang ${ }^{1,2^{*}}$ 6

$7 \quad{ }^{1}$ Department of Aquaculture, National Taiwan Ocean University, Keelung 20224, Taiwan

$8{ }^{2}$ Center of Excellence for the Oceans, National Taiwan Ocean University, Keelung 20224,

9 Taiwan

$10{ }^{3}$ Laboratory Biology of Aquatic Organisms and Ecosystems (BOREA), Muséum National 11 d'Histoire Naturelle, CNRS, IRD, Sorbonne Université, Université de Caen Normandie, 12 Université des Antilles, 75231 Paris Cedex 05, France

13

14

15 Running title: Expression profiles of $f s h b, l h b$, gpa, gnrhrl, gnrh, cyp19alb, fshr and lhcgr 16 in black porgy.

17

18

20 Ching-Fong Chang: b0044@email.ntou.edu.tw; Sylvie Dufour: sylvie.dufour@mnhn.fr 21 


\section{ABSTRACT}

Previous studies revealed an estradiol (E2) -dependent peak in brain activity, including neurosteroidogenesis and neurogenesis in the black porgy during the gonadal differentiation period. The brain-pituitary-gonadotropic axis is a key regulator of reproduction and may also be involved in gonadal differentiation, but its activity and potential role in black porgy during the gonadal differentiation period is still unknown. The present study analyzed the expression of regulatory factors involved in the gonadotropic axis at the time of gonadal differentiation (90, 120, 150 days after hatching [dah]) and subsequent testicular development (180, 210, 300 dah). In agreement with previous studies, expression of brain aromatase cyp 19alb peaked at $120 \mathrm{dah}$, and this was followed by a gradual increase during testicular development. The expression of gonadotropin subunits increased slightly but not significantly during gonadal differentiation and then increased significantly at $300 \mathrm{dah}$. In contrast, the expression of brain gnrhl and pituitary gnrh receptor 1 (gnrhrl) exhibited a pattern with two peaks, the first at 120 dah, during the period of gonadal differentiation, and the second peak during testicular development. Gonad $f s h r$ and lhcgr increased during gonadal differentiation period with highest transcript level in prespawning season during testicular development. This suggests that the early activation of brain gnrhl, pituitary gnrhrl and gths, and gonad gthrs might be involved in the control of gonadal differentiation. E2 treatment increased brain cyp19alb expression at each sampling time, in agreement with previous studies in black porgy and other teleosts. E2 also significantly stimulated the expression of pituitary gonadotropin subunits at all sampling times, indicating potential E2-mediated steroid feedback. In contrast, no significant effect of E2 was observed on gnrh1. Moreover, treatment of AI or E2 had no statistically significant effect on brain gnrhl transcription levels during gonadal differentiation. This indicated that the early peak of gnrhl expression during the gonadal differentiation period is E2-independent and therefore not directly related to the E2-dependent peak in brain neurosteroidogenesis and neurogenesis also occurring during this period in black porgy. Both E2-independent and E2-dependent mechanisms are thus involved in the peak expression of various genes in the brain of black porgy at the time of gonadal differentiation.

\section{Highlights:}

1. Expression of brain gnrhl and pituitary gnrh receptor 1 transcripts peaked during gonadal differentiation.

2. Brain gnrhl expression showed an E2-independent pattern during gonadal differentiation.

3. Both E2-independent and E2-dependent mechanisms are involved in the peak expression of various genes in the brain during gonadal differentiation.

Keywords: brain, teleost, gonadotropic axis, gnrh, cyp19alb, gonadal differentiation 


\section{Introduction}

Black porgy is a hermaphroditic protandrous teleost, with functional males for the first two years of life and sex change to females during the third year. Previous studies showed that during the period of gonadal differentiation (90-150 days after hatching [dah]), the brain exhibited increased estradiol (E2) synthesis, cell proliferation, and neurogenesis. The expression of neurosteroidogenesis-related genes, including star, brain-type aromatase cyp19alb, and nuclear estrogen receptors, peaked at 120 dah (Tomy et al., 2009; Tomy et al., 2007; Wu et al., 2010). Exogenous E2 treatment stimulated neurosteroidogenesis and neurogenesis, while aromatase inhibitor (AI) decreased brain cell proliferation, which indicated that $\mathrm{E} 2$ played important roles in the induction of early brain development (Lin et al., 2016). In contrast, no significant differences in brain gene expression or neurogenesis were found in castrated fish compared to controls, further supporting the idea that the peak in early brain activity was controlled by locally produced brain E2 and was independent of the gonads (Lin et al., 2016).

In teleosts, as in mammals, the neuropeptide gonadotropin-releasing hormone ( $\mathrm{GnRH})$ acts on pituitary gonadotrope cells via binding to the GnRH receptor (GnRH-R) and stimulates the biosynthesis and release of GTHs (gonadotropin hormones; luteinizing hormone $[\mathrm{LH}]$ and follicle-stimulating hormone $[\mathrm{FSH}])$. GTHs binds to GTH receptors (GTH-R; follicle-stimulating hormone receptor [FSH-R] and luteinizing hormone/chorionic gonadotropin receptor [LHCG-R]) on gonad and directly control reproductive function by inducing gonadal steroidogenesis and gametogenesis. The gonadal steroids exert feedback on the brain-pituitary-gonadotropic axis (Amano et al., 1997).

Steroid hormones, particularly E2, play important roles in sex determination and reproduction. Brain steroids may be originally synthesized in the gonad and reach the brain via the general circulation. The brain may also produce steroids locally including E2 via neurosteroidogenesis (Diotel et al., 2011). Brain aromatase expression in teleosts is exclusive in radial glial cells and is found in olfactory bulbs, telencephalon, ventral diencephalon and pituitary gland, with the highest expression at preoptic area and hypothalamus (Forlano et al., 2001; Menuet et al., 2003; Strobl-Mazzulla et al., 2005). The expression levels of brain aromatase activity in teleosts is higher than any other vertebrates, which has been suggested a mechanism of continual neurogenesis found in fish (Forlano et al., 2001; Pellegrini et al., 2007). Gene expression of cyp19alb in black sea bass was analyzed in brain and pituitary during reproductive development and sex change; elevated cyp 19a1b expression was found in the brain at stage of female vitellogenic growth and in the pituitary at stage of male spermiating (Breton et al., 2015). In female ricefield eel, Cyp19a1b colocalized with Lhb in pituitary was observed by immunohistochemistry (Zhang et al., 2014). The immunoreactive levels and colocalization frequency increased during gametogenesis toward maturation, which suggested a relationship between pituitary 
100 Cyp19a1b and Lhb during vitellogenesis (Zhang et al., 2014). Pituitary cyp19alb but not 101 brain cyp19alb involved in the regulation of social behavior in cichlid fish (Ramallo et al., 102 2017). Higher levels of E2 or cyp19alb were detected in brain of male pejerrey and rainbow 103 trout during gonadal differentiation (Strobl-Mazzulla et al., 2008; Vizziano-Cantonnet et al., 2011). But studies about pituitary cyp19alb during gonadal differentiation is limited.

The brain-pituitary-gonadotropic axis is well known for its role in controlling reproductive functions and may also play a role in gonadal differentiation in fish (Senthilkumaran et al., 2015). In European sea bass, for example, higher expression levels of brain gnrh genes and pituitary $f_{s} h b$ were observed during gonadal differentiation period (Moles et al., 2007). As shown by immunostaining in pejerrey, Gnrh neurons and Fshb- and Lhb-positive pituitary cells were detectable before gonadal differentiation, which suggested a role for the brain-pituitary-gonadotropic axis in this period (Miranda et al., 2003; Miranda et al., 2001). In contrast, in Nile tilapia, according to results from qPCR and immunostaining, $f s h b$ and $l h b$ in the pituitary were not related to gonadal differentiation (Yan et al., 2012).

115 Previous studies from our group investigated the brain-pituitary-gonadotropic axis in 116 black porgy. Annual profiles analyzed by radioimmunoassay showed an increase in Gnrh1 117 and Lh levels during sexual maturation in 1- and 2-yr-old fish (Du et al., 2005). In 2+- to 118 3-yr-old black porgy, higher levels of plasma Lh during the nonspawning season were 119 detected in male fish than in fish that sex-changed to females later in the spawning season 120 (Du et al., 2005). Two types of GnRH receptors, gnrhrl and gnrhr2, were cloned and analyzed in 2+- and 3-yr-old black porgy (Lin et al., 2010). The tissue distribution revealed that gnrhrl was strongly expressed in the pituitary, and gnrhr2 (40 cycles) was expressed at very low level as compared to gnrhrl (30 cycles) and was mainly expressed in gonad and kidney by semi-quantitative PCR. Sex steroids (E2 and T) and LHRH analog increased the expression of gnrhrl, but not gnrhr2, in pituitary in vivo or pituitary cells in vitro (Lin et al., 2010). These results indicated that gnrhrl may play a more important role in the pituitary than does gnrhr2. An increase in the pituitary expression of gnrhrl was found during sexual maturation in 2+-yr-old black porgy (Lin et al., 2010). E2 treatment stimulated Lh levels in pituitary and plasma in 2-yr-old fish (Chang et al., 1991; Du et al., 2001; Lee et al., 1999;

130 Lee et al., 2000; Yen et al., 2002). Increased levels of plasma Lh and plasma E2 during the 131 prespawning and spawning seasons were correlated with the natural sex change in 3-yr-old 132 black porgy (Chang et al., 1994; Lee et al., 2000). Higher transcript levels of $f$ shr and lhcgr 133 in the bisexual testicular tissue compared with that of ovarian tissue was found in 1+- and 134 2+-yr-old black porgy ( $\mathrm{Du}$ et al., 2005; Wu et al., 2016). Whereas many studies have analyzed the brain-pituitary-gonadotropic axis during sexual maturation and sex change, 136 data during gonadal differentiation are limited: only one study reported the profile of brain 137 Gnrh by radioimmunoassay during this period ( $\mathrm{Du}$ et al., 2005), with no data on 
gonadotropins.

139 The present study aimed to investigate the activity of the brain-pituitary-gonadotropic 140 axis in black porgy during gonadal differentiation. Quantitative real-time PCRs were used to 141 analyze gene expression of $f s h b$ and $l h b$ subunits, common glycoprotein alpha subunit ( $g p a$ ), $142 \mathrm{GnRH}$ receptor 1 (gnrhrl), and brain-type aromatase (cyp19alb) in the pituitary and of 143 gnrh1, gnrh2, gnrh3, and cyp19alb in anterior brain at the time of gonadal differentiation 144 (90-150 dah). Comparisons were made with their expression levels during subsequent 145 testicular development in sexually maturing males (up to 300 dah). The effects of E2 146 treatment on these brain and pituitary gene expression levels during the periods of gonadal 147 differentiation and testicular development were also investigated to infer potential 148 E2-dependent regulatory mechanisms.

\section{Materials and methods}

\subsection{Animals}

Juvenile (75 dah) black porgy were obtained from an aquaculture farm and acclimated in seawater (salinity $33 \mathrm{ppt}$ ) to the ponds at the National Taiwan Ocean University culture station (NTOU; Keelung, Taiwan). These experimental fish were kept in indoor ponds with natural temperature until 90 dah before starting the experiment. Water temperatures ranged from $19^{\circ} \mathrm{C}$ to $26^{\circ} \mathrm{C}$. Samples were collected from May (90 dah) to Dec (300 dah). The fish were fed twice a day ( $8 \%$ of their body weight in total feed per day) with commercial feed (Fwa Sou Feed, Taichung, Taiwan). All the procedures and experiments were approved by the NTOU Institutional Animal Care and Use Committee and were conducted in accordance with the animal experimentation procedure guidelines.

\subsection{Experimental design}

Black porgy is a protandrous fish with gonadal differentiation at 120-150 dah followed by testis development until the stage of functional testes and spawning (at approximately 1 year old). Previous studies in black porgy have reported that the expression levels of neurosteroidogenesis-related genes, including star, cyp19alb, and nuclear estrogen receptors, peak in the early brain during gonadal differentiation (Tomy et al., 2009; Tomy et al., 2007; Wu et al., 2010). Furthermore, we already know that the brain changes in this period are controlled by locally produced E2 and are independent from gonadal factors (Lin et al., 2016).

In the present study, brain, pituitary and gonadal samples were collected from 90-300 dah fish during the gonadal differentiation period (at 90, 120 and 150 dah) and the testicular development period (at 180, 210 and 300 dah) to analyze the expression profiles of genes involved in the brain-pituitary-gonadotropic axis. The effects of E2 on gene expression were 
also examined. To investigate the effects of E2, fish were treated in vivo with E2 from 90 dah until the end of the experiment. The E2-treated group received $6 \mathrm{mg}$ E2 (Sigma-Aldrich, St. Louis, MO)/kg feed, according to the dosage previously established in black porgy (Lee et al., 2000). The control group was fed the same diet but without E2. Brain and pituitary samples from E2-treated fish were collected along with control fish during the gonadal differentiation period (at 120 and 150 dah) and the testicular development period (at 180, 210 and 300 dah). Gonad samples from control and E2-treated fish were collected during the testicular development period (at 180, 210, 240 and 300 dah). For fish at 90 dah, a single group of initial control fish was collected. To further confirm the effects of E2 on gene expression, we tested the effect of aromatase inhibitor (AI; 1,4,6-androstatrien3,17-dione; Steraloids, Newport, RI) during the gonadal differentiation period. Fish at 90 dah were divided into three groups: E2, AI, and control groups. The control group was fed the same diet but without E2 ( $6 \mathrm{mg} / \mathrm{kg}$ feed) or AI ( $20 \mathrm{mg} / \mathrm{kg}$ feed). The E2 and AI dosages were established previously in black porgy (Lee et al., 2000; Lee et al., 2002). Brain samples were collected at 90, 120 and 150 dah.

\subsection{Biometry and brain and pituitary sampling}

Fish were anesthetized with 0.1\% 2-phenoxyethanol in seawater and were sacrificed by decapitation. The biometric parameters body weight (BW) and body length (BL) were measured and are reported in Supporting Information Table S1. No statistically significant differences in BW or BL were found between the control and E2-treated groups (NS).

The brain and pituitary were dissected out. The anterior brain $(\mathrm{n}=8$ individuals per group and sampling time) was further dissected into two parts: the telencephalon, including olfactory bulbs (TE), and the di-/mesencephalon, including the hypothalamus, preoptic area and thalamus (DME). The schematic drawings of brain dissection are shown in Figure 1. Pituitaries were pooled into groups of ten (90, 120 and 150 dah fish) or of five (180, 210 and 300 dah fish), and 4 pools were collected per group and sampling time. Gonads were also collected and analyzed: samples were pooled into groups of eight (3 pools for 90, 120 and 150 dah fish), four (4 pools for 180 dah fish) or two (5 pools for 210 and 240 dah fish); and 10 individual gonads for 300 dah fish. The samples were stored at $-80^{\circ} \mathrm{C}$ until qPCR analysis.

\subsection{Histology and immunocytochemistry of gonads}

Gonad samples from control fish or E2-treated fish were collected to examine the gonadal status by histological analysis. The gonad developmental stages were defined according to previous reports (Tomy et al., 2007; Wu et al., 2008a; Wu et al., 2008b), both E2 and AI treatments resulted in the regression of testicular tissue, development of oogonia/primary oocytes and growth of ovarian tissue. Samples were quickly removed, 
214 fixed for $16 \mathrm{~h}$ with $4 \%$ paraformaldehyde in $0.1 \mathrm{M}$ sodium phosphate buffer with saline 215 (PBS, pH 7.4), and then dehydrated through a graded methanol series, embedded in paraffin, 216 and subjected to serial sectioning into $6 \mu \mathrm{m}$ transverse sections for $\mathrm{H} \& \mathrm{E}$ staining and 217 immunostaining.

218 After dewaxing and rehydrating, gonad sections were immunostained for Pcna (S phase-related proliferating cell nuclear antigen) as a marker of cell proliferation using the standard avidin-biotinylated-peroxidase complex kit (ABC kit; Vector Laboratories, Burlingame, CA). The gonad sections were incubated for $10 \mathrm{~min}$ in $3 \% \mathrm{H} 2 \mathrm{O} 2$, for $1 \mathrm{~h}$ in $5 \%$ skim milk, and overnight at $4^{\circ} \mathrm{C}$ with primary antibodies (Pcna; 1:200; DakoCytomation, Glostrup, Denmark). After washing with PBS with $0.1 \%$ Tween-20, the sections were incubated with a biotinylated goat IgG antibody (1:2,000; Vector Laboratories) and finally incubated in $\mathrm{ABC}$ solution. The peroxidase reaction was visualized with a solution of 3,3'-diaminobenzidine (DAB; Sigma-Aldrich) and then observed and photographed under a microscope (BX51; Olympus, Tokyo, Japan).

\subsection{Measurement of gene transcripts by qPCR analysis}

TRIzol reagent (Invitrogen) was used, and total RNA was extracted from pituitaries and dissected brain tissues. Total RNA was reverse transcribed to first-strand cDNA using Superscript III (Invitrogen) with oligo(dT) ${ }_{12-18}$ primers (Promega, Madison, WI) according to the manufacturer's protocol. First-strand cDNA was used for qPCR analysis. qPCR was conducted using a 7500 Real-Time PCR System (Applied Biosystems, CA) and SYBR Green as described in our previous study (He et al., 2003).

The pituitary transcript levels of the gonadotropin beta subunits $f s h b, l h b$, and of the common glycoprotein alpha subunit gpa were analyzed. Two types of GnRH receptors, gnrhrl and gnrhr2, were also analyzed. However, the gene expression of pituitary gnrhr2 was very low $(\mathrm{Ct}>37.0$ to Undetectable), so that only the results for gnrhrl are presented.

The transcript levels of the three types of GnRH present in the black porgy, gnrhl, gnrh2, and gnrh3, were analyzed in dissected brain parts. Gnrh1 transcripts could be measured in both the telencephalon and di-/mesencephalon, while gnrh2 and gnrh3 transcripts were measurable in the di-/mesencephalon and telencephalon, respectively.

The transcript levels of cyp19alb were analyzed in the pituitary and dissected brain parts. Previous data from tissue distribution in 1+-yr-old black porgy showed that the "gonad form of aromatase", cyp19ala, was expressed only in gonad tissue and not in the brain (Wu et al., 2016). Conversely, we demonstrated that the "brain form of aromatase", cyp19a1b, was only expressed in the brain and pituitary (Supporting Information Figure S1). Therefore, the brain form of aromatase (cyp19alb) was analyzed by qPCR in pituitary and brain parts in the present study.

The transcript levels of gonadotropin receptors $f s h r$ and $l h c g r$ were analyzed in the 
gonadal samples of black porgy.

As an internal control, gapdh (glyceraldehyde 3-phosphate dehydrogenase) was used to normalize the gene expression level. No significant changes in the expression levels of gapdh were found among the groups $(P>0.05)$.

The accession numbers of the sequences analyzed in this study, and gene-specific primers and annealing temperatures are described in Supporting Information Table S2. The primer specificity is shown in Supporting Information Figure S2.

\subsection{Statistics}

The data are presented as the mean \pm SEM (standard error of the mean). Statistical analyses were performed by one-way analysis of variance (ANOVA) followed by Duncan's test using Statistical Package for the Social Sciences (SPSS). Student's $t$-test was also conducted to determine significant differences between treatments. A value of $P<0.05$ was considered statistically significant.

\section{Results}

\subsection{Gonadal differentiation and testicular development}

Undifferentiated gonad tissue with early germ cells was observed in 90 dah fish (Fig. 2, A1). Differentiated gonads with ovarian cavities were found in 120 dah fish (Fig. 2, B1). Early spermatogonia (type A) began to appear in 120 dah (Fig. 2B1) and 150 dah fish (Fig. 2, C1). Lobular testicular tissue with late spermatogonia (type B) was observed in 180 dah (Fig. 2D1) and 210 dah fish (Fig. 2E1). The characteristics of the different male germ cells (type A and type B spermatogonia) are shown in Supporting Information Figure S3. To further examine the cell activity, Pcna was used as a cell proliferation marker to confirm the gonadal status. According to the Pcna immunostaining, undifferentiated gonads had fewer Pcna-positive cells in 90 dah fish (Fig. 2A2 and A2'). Proliferating activity of gonadal cells was dramatically increased during gonadal differentiation in 120 dah and 150 dah fish (Fig. 2B2, B2', C2, and C2'). Large numbers of Pcna-positive germline cells were observed in 180 dah (Fig. 2D2) and 210 dah fish (Fig. 2, E2).

282

After E2 administration, development of ovarian tissue was found in protandrous black porgy. Primary oocytes and oogonia appeared in gonadal tissues during gonadal differentiation stage (Fig. 2F1 and F1'). During gonadal development stage, large numbers of primary oocytes were observed in these ovarian tissues at 180 dah fish (E2 administration for 3 months) (Fig. 2G1 and G1'). Pcna-positive oogonia were found in the gonads of E2-treated fish during gonadal differentiation and development period (Fig. 2F2, F2', G2 described in our previous study (Wu et al., 2008a). 
Combining these data with our previous studies (Lee et al., 2008; Wu et al., 2008a), gonadal differentiation occurs at approximately 120 dah in black porgy. In protandrous black porgy, the period from the completion of gonadal differentiation to the first spawning season is considered the testicular development stage.

\subsection{Expression profiles of pituitary gonadotropin subunits, gnrh receptor 1 and aromatase}

Gene expression profiles were measured by qPCR during the period of gonadal

297

298

299

300

301

302

303

304

305

306

307

308

309

310

311

312

313

314

315

316

317

318

319

320

321

322

323

324

325

326

327 differentiation (from 90 dah to 150 dah) and during the subsequent period of testicular development (from 180 dah to 300 dah) for comparison (Fig. 3).

The transcript levels of $l h b$ were slightly but not significantly increased at the time of gonadal differentiation (120 dah) compared to those at 90 dah (2.1-fold, NS). Lhb transcript levels increased markedly during testicular development to reach a 26.0 -fold-higher value at 300 dah than at 90 dah $(P<0.01)$. Fshb transcript levels did not vary during gonadal differentiation but were markedly increased at 300 dah (26.4-fold increase compared to 90 dah, $P<0.05)$. The pituitary gpa transcript levels were slightly but significantly increased at 300 dah (4.1-fold increase compared to 90 dah, $P<0.05$ ).

The relative expression of gnrhrl peaked at the time of gonadal differentiation at 120 dah (3.9-fold compared to 90 dah, $P<0.01)$. A further increase was observed during testicular development at 180 dah (6.6-fold compared to 90 dah, $P<0.01)$, but transcript levels then decreased to reach values at 300 dah (3.8-fold compared to 90 dah, $P<0.05)$ similar to those at 120 dah.

We also measured cyp19alb pituitary transcript levels and observed a gradual increase during the period of gonadal differentiation (1.6-fold at 120 dah, NS; 3.4-fold at 150 dah, $P$ $<0.05$; compared to $90 \mathrm{dah}$ ) and further increase during testicular development (3.6-fold at 180 dah, $P<0.01$; 4.4-fold at 210 dah, $P<0.05$; 4.8-fold at 300 dah, $P<0.01$; compared to 90 dah). However, there was no peak expression of cyp19alb in the pituitary as compared to a peak expression in the brain during gonadal differentiation.

\subsection{Expression profiles of brain gnrh genes and aromatase gene}

qPCR was performed on telencephalon and di-/mesencephalon from 90 dah to 300 dah fish to determine the gene expression profiles during the periods of gonadal differentiation and testicular development (Fig. 4).

The transcript levels of gnrhl increased significantly during the period of gonadal differentiation, with a peak at 120 dah in the telencephalon (2.8-fold compared to 90 dah, $P$ $<0.05)$ and di-/mesencephalon (2.5-fold compared to 90 dah, $P<0.01)$. An increase was also observed during testicular development in both the telencephalon and di-/mesencephalon, with levels at 300 dah similar to those at 120 dah (2.6-fold at 300 dah, $P$ $<0.01$ for telencephalon; 3.1-fold at $300 \mathrm{dah}, P<0.01$ for di-/mesencephalon; compared to 
90 dah telencephalon and 90 dah di-/mesencephalon, respectively).

Transcript levels of gnrh2 in the di-/mesencephalon gradually increased during the period of gonadal differentiation with a peak at 150 dah (2.4-fold compared to 90 dah, $P<$

3310.01 ) and then gradually decreased during testicular development such that the level at 300 dah was similar to that at 90 dah.

Concerning gnrh3, no significant variation was observed during gonadal differentiation, with only a slight increase $(1.4$-fold compared to 90 dah, $P<0.05)$ at one sampling time (180 dah) during testicular development.

We also measured cyp19alb brain transcript levels and observed peaks of expression at 120 dah in the telencephalon (2.2-fold compared to 90 dah, $P<0.01$ ) and di-/mesencephalon (2.3-fold as compared to 90 dah, $P<0.001)$ during gonadal differentiation. These results were in agreement with our previous study (Lin et al., 2016). A large, gradual increase was observed in telencephalon during testicular development, with transcript levels at 300 dah reaching values 22.9-fold higher than at 90 dah $(P<0.001)$, while a more moderate but also significant increase was observed in di-/mesencephalon (5.2-fold compared to 90 dah, $P<0.001$ ).

\subsection{Expression profiles of gonadal gonadotropin receptors}

qPCR was performed on gonad from 90 dah to 300 dah fish to determine the gene expression profiles during the periods of gonadal differentiation and testicular development (Fig. 5).

The transcript levels of lhcgr were increased during gonadal differentiation period (2.4-fold at 120 dah, NS; 2.6-fold at 150 dah, $P<0.01$; compared to 90 dah). Transcript levels of lhcgr gradually increased during the period of testicular development with a peak at 240 dah (4.3-fold compared to $90 \mathrm{dah}, P<0.01)$. The relative expression of $f s h r$ significantly increased during gonadal differentiation period (2.9-fold at 120 dah, $P<0.01$; 3.0-fold at 150 dah, $P<0.01$; compared to 90 dah). A gradual increase of $f s h r$ was observed during testicular development to reach a 3.7-fold-higher value at 240 dah than at 90 dah $(P$ $<$ 0.01). Similar expression patterns of gonadotropin receptors were found, both the transcript levels of $f s h r$ and lhcgr gradually increased during the period of testicular development and then significantly decreased at 300 dah that the level was similar to that at 90 dah.

\subsection{Effect of E2 on transcript levels}

Based on our previous study that demonstrated estradiol-dependent activation of brain neurogenesis and neurosteroidogenesis during the period of gonadal differentiation (Lin et al., 2016), we investigated the effect of E2 treatment on the expression of our genes of interest in the present study. 


\subsubsection{Effect of E2 on pituitary and brain transcript levels of aromatase}

qPCR was performed on fish at 90 dah to 300 dah to investigate the effect of E2

369

370

371

372

373

374

375

376

377

378

379

380

381

382

383

384

385

386

387

388

389

390

391

392

393

394

395

396

397

398

399

400

401

402

403 treatment on cyp19alb transcript levels during periods of gonadal differentiation and testicular development (Fig. 6).

E2 showed a positive effect on cyp19alb expression in the brain, with significant increases observed in telencephalon and di-/mesencephalon at each sampling time, during both gonadal differentiation and testicular development periods. In telencephalon, expression levels ranging from 5.5-fold to 15.3-fold higher than the respective control group were observed $(P<0.01$ to $P<0.001)$. A similar positive effect of E2 was observed in di-/mesencephalon, which showed expression levels 3.0-fold to 9.6-fold higher than in each respective control group $(P<0.01$ to $P<0.001)$. The significant stimulatory effect of E2 on cyp19alb during gonadal differentiation in dissected brain parts is in agreement with our previous study (Lin et al., 2016).

The effect of E2 on the pituitary cyp19alb was different from brain cyp19alb. The E2 effect on pituitary cyp19alb was not significant at all sampling times and was limited to 120 dah and 300 dah. The cyp19alb expression after E2 treatment in the pituitary was 2.7-fold higher than that in the control at 120 dah $(P<0.05)$ and was 2.9 -fold higher at 300 dah $(P<$ $0.01)$.

\subsubsection{Effect of E2 on pituitary transcript levels of gonadotropin subunits and gnrhrl}

Transcript level analysis was performed by qPCR to investigate the E2 effect during the period of gonadal differentiation and testicular development (Fig. 7).

Stimulatory effects of E2 on pituitary $f s h b$ and $l h b$ subunit expression were observed at all sampling times during the gonadal differentiation and testis development periods. Pituitary $f s h b$ showed a strong response to E2, with expression levels 3.0-fold to 20.0-fold higher than each respective control group $(P<0.05$ to $P<0.001)$. Lhb showed a smaller response to E2 compared to $f s h b$ : 1.5 -fold to 3.9 -fold increases were observed $(P<0.05$ to $P<0.01)$.

A significant response of gpa to E2 was observed only during the testicular development period, with a 2.1-fold to 5.9-fold increase compared to the respective control groups $(P<0.05$ to $P<0.001)$. E2 had no significant effect on gpa during the gonadal differentiation period.

A slight but significant stimulatory effect of E2 on gnrhrl transcript levels was observed during gonadal differentiation, with a 2.3-fold increase at 120 dah $(P<0.05)$ and a 1.8-fold increase at $150 \mathrm{dah}(P<0.05)$, as well as a slight response with a 1.8 -fold increase at 300 dah $(P<0.05)$, compared to their respective control groups.

Altogether, E2 treatment significantly stimulated pituitary $f s h b$, lhb, and gnrhrl 
404

405

406

407

408

409

410

411

412

413

414

415

416

417

418

419

420

421

422

423

424

425

426

427

428

429

430

431

432

433

434

435

436

437

438

439

440

441

expression during the gonadal differentiation period, while there was no significant effect on gpa at that time. During testicular development, E2 showed positive effects on gonadotropin subunits ( $f$ shb, lhb, gpa) and gnrhrl but only at a limited sampling time (300 dah).

\subsubsection{Effect of E2 on brain transcript levels of gnrh genes}

qPCR was performed on telencephalon and di-/mesencephalon to investigate the E2 effect on gnrh genes in fish from 90 dah to 300 dah (Fig. 8).

E2 had no effect on gnrhl expression in the telencephalon at any sampling time during gonadal differentiation and testicular development. Similarly, E2 did not affect gnrhl expression in the di-/mesencephalon, except at one sampling time (210 dah: 2.0-fold compared to the respective control group, $P<0.05$ ).

A slight but significant stimulatory effect of E2 on gnrh3 was observed in the telencephalon at most sampling times (1.6-fold to 1.8-fold higher than each respective control group, $P<0.05)$ but not at 300 dah $(1.3$-fold compared to the respective control group, $P>0.05)$.

No effect of E2 on gnrh2 was found in di-/mesencephalon, except for the samples taken at 120 dah, which showed a slight increase of 1.4 -fold $(P<0.05)$ compared to the respective control group.

\subsubsection{Effect of E2 on gonadal transcript levels of gonadotropin receptors}

qPCR was performed on gonad to investigate the E2 effect on $f$ shr and lhcgr genes in fish from 180 dah to 300 dah (Fig. 9).

Inhibitory effects of E2 on gonadotropin receptors expression were observed at most sampling times but not at 300 dah ( $f$ shr, 1.5-fold compared to the respective control group, NS; lhcgr, 1.9-fold compared to the respective control group; $P>0.05)$. Fshr showed a strong response to E2, with expression levels 0.1-fold lower than each respective control group $(P<0.05$ to $P<0.001)$. Lhcgr showed a smaller response to E2 compared to $f$ shr: 0.5 -fold to 0.2 -fold decreases were observed $(P<0.05$ to $P<0.01)$.

\subsection{Effect of AI on brain transcript levels of gnrh1 and cyp19alb}

Our previous studies reported that AI-feeding treatment reduced brain aromatase enzyme activity by 70-80\% (Lee et al., 2002). We investigated the effect of E2 and AI treatment on the expression of our genes of interest in the present study. qPCR was performed on telencephalon and di-/mesencephalon to investigate the AI effect on gnrhl and cyp 19alb in fish during gonadal differentiation period (Fig. 10).

No statistically significant $(P>0.05)$ differences on $g n r h l$ expression were found in the telencephalon or di-/mesencephalon between the control and AI-treated groups. 
Similarly, E2 had no effect on gnrhl expression in the telencephalon or di-/mesencephalon at any sampling time.

As an experimental positive control, AI reduced significantly cyp 19a1b expression in telencephalon, which showed expression levels with 0.5 -fold $(P<0.01)$ and 0.6 -fold $(P<$ 446 0.01) lower than the respective control group at 120 and 150 dah. A similar inhibitory effect of AI on cyp19alb in di-/mesencephalon with expression levels of 0.2 -fold $(P<0.001)$ at 120 dah and 0.5 -fold $(P<0.05)$ at 150 dah lower than the each respective control group were observed. Positive effect of E2 on cyp19alb was observed in di-/mesencephalon and telencephalon, which showed expression levels 2.2-fold to 14.0-fold higher than the respective control group $(P<0.05$ to $P<0.001)$.

452

453

454

455

456

\section{Discussion}

\subsection{Activation of gene expression in the brain-pituitary-gonadotropic axis during} gonadal differentiation and testicular development in black porgy

In previous studies, we revealed a peak in the brain activity of neurosteroidogenesis and neurogenesis during the gonadal differentiation period in the black porgy (Tomy et al., 2009; Tomy et al., 2007; Wu et al., 2010). We further demonstrated that this peak expression in the early brain was controlled by locally produced brain E2 and was independent of the gonads (Lin et al., 2016).

In the present study, we observed a significant peak in the expression of brain aromatase cyp19alb at 120 dah, during the period of gonadal differentiation. This result is in agreement with our previous studies supporting the role of aromatase and locally produced brain E2 in the peak of brain activity and neurogenesis at this time (Lin et al., 2016). Comparison with the subsequent period of testicular development revealed a further large increase in brain aromatase expression, supporting further roles of aromatase during testis maturation, including mediation of feedback activities exerted by aromatizable gonadal androgens (Lee et al., 2001; Lee et al., 2000; Lee et al., 2002).

Concerning the gonadotropic axis, a small but not significant increase in pituitary gonadotropin subunit transcript levels was observed during the gonadal differentiation period, while a large increase was measured during subsequent testicular development. This large increase in transcript levels is in agreement with the involvement of gonadotropin hormones in the control of gonadal maturation and reproduction. Interestingly, pituitary gnrhrl exhibited a very different pattern, with two significant peak increases, at 120 dah and at 300 dah, instead of a high increase during maturation. A similar pattern of increases at 120 dah and at 300 dah was also observed for brain gnrhl. For the gonadotropin receptors analyzed in gonads, the gene expressions of gonadal $f s h r$ and $l h c g r$ increased during 
testicular development, but significant decrease of gthrs gene expression was found from 240 dah (Oct) to 300 dah (Dec). Similar decreased patterns were also found in 1+-yr-old black porgy (Wu et al., 2016): significantly higher expression was found in prespawning season (Sep) and drop dramatically in spawning season (Dec)(15.7-fold decrease for $f$ shr; 23.5-fold decrease for lhcgr).

Regarding the brain-pituitary-gonadotropic axis in black porgy, previous studies focused on regulations during gonadal maturation, sex change and reproduction (Chang et al., 1994; Chang and Yueh, 1990; Chang et al., 1991; Du et al., 2001; Du et al., 2005; Lee et al., 1999; Lee et al., 2000; Lin et al., 2010; Yen et al., 2002). Only one study investigated GnRH during the period of gonadal differentiation ( $\mathrm{Du}$ et al., 2005). This previous study from our group, using HPLC and radioimmunoassay, revealed two similar peaks of Gnrh1 contents, at 120-150 dah and at 300-360 dah, during the nonspawning and spawning seasons, respectively. The gnrhl gene expression patterns analyzed in the present study are in good agreement with the peak of radioimmunoassayable Gnrh contents reported by Du et al. (2005) at the same times. In particular, they support a peak expression of GnRH1 during the period of gonadal differentiation.

The parallel expression patterns for gnrhl and gnrhrl observed in the present study might suggest a close relationship between gnrhl and gnrhrl and their potential activation and roles during gonadal differentiation.

\subsection{Possible role of gonadotropic axis in black porgy gonadal differentiation?}

The brain-pituitary-gonadotropic axis is well known to regulate sexual maturation and reproduction, and this axis may also play a role in gonadal differentiation in some fish species (Senthilkumaran et al., 2015). A peak in the activity of neurosteroidogenesis and neurogenesis was found in the brain of black porgy during gonadal differentiation. The factors triggering peak expression are unknown, and whether the gonadotropic axis hormones are involved in gonadal differentiation in black porgy has been unclear.

During sex differentiation of European sea bass, increased expression of GnRH1 and GnRH3 was observed in the brain by semiquantitative PCR and ELISA. The increase in GnRH1 was correlated with gnrhr gene expression in the pituitary during this period (Moles et al., 2007). In European sea bass, three Gnrhs were detectable in the brain and pituitary by ELISA during gonadal differentiation (Moles et al., 2007; Rodriguez et al., 2000). However, only Gnrh1 showed a significant increase during maturation, along with higher plasma Lh levels and plasma testosterone levels in male sea bass (Rodriguez et al., 2000). All three Gnrhs were proposed to be involved in achieving gonadal differentiation, while Gnrh1 may be the most relevant form in the regulation of the first spawning season in male sea bass (Rodriguez et al., 2000). According to immunostaining results in pejerrey, Gnrh-, Fshb-, and Lhb-positive cells appeared in brain or pituitary before gonadal differentiation, which 
518 suggested a role for the brain-pituitary-gonadotropic axis in this period (Miranda et al., 519 2003; Miranda et al., 2001). Increased Gnrh-positive neurons were found in pejerrey during 520 the sensitive period of sex determination, which indicated the active activity of 521 brain-pituitary-gonadotropic axis in sex differentiation (Miranda et al., 2003; Somoza et al., 2006). Gnrh-positive neurons in Nile tilapia were detected as early as 5 dah before the

523

524

525

526

527

528

529

530

531

532

533

534

535

536

537

538

539

540

541

542

543

544

545

546

547

548

549

550

551

552

553

554

555 critical period of sex differentiation (7-21 dah), and showed sexually dimorphic patterns (Swapna et al., 2008). However, in the Nile tilapia and Malabar grouper, qPCR and immunostaining results indicated that changes in pituitary gonadotropin expression levels were not critical for gonadal differentiation (Munakata and Kobayashi, 2010; Yan et al., 2012). The authors suggested that gonadal $f s h r$ transcript levels in Nile tilapia would be a key factor involved in determining gonadal differentiation (Yan et al., 2012). In zebrafish, gonadotropins or gonadotropin receptors may not involve in gonadal differentiation. The TALEN-disruption of gonadotropins and gonadotropin receptors delayed spermatogenesis in zebrafish, but not much difference was observed between control and mutant male fish during gonadal differentiation (Zhang et al., 2015a; Zhang et al., 2015b).

The role of the brain-pituitary-gonadotropic axis in gonadal differentiation may be species-specific and different among teleost fishes. In the present study, similar but not identical to results from European sea bass, black porgy showed increased expression of gnrhl in anterior brain and of gnrhrl in the pituitary during gonadal differentiation. Pituitary gonadotropin subunit transcript levels showed a slight but not significant increase during this period. The gene expressions of lhcgr and $f s h r$ in gonads significantly increased during gonadal differentiation. These results support the possibility of the activation of the axis of brain gnrhl, pituitary gnrhrl and gonadotropin subunits, and gonad gthrs at the time of gonadal differenciation. It might be just a correlation, but also that the activation of this axis may involve in the activation of gonadal differentiation in black porgy. We hypothesize that gnrhl-gnrhrl might thus involve in stimulating gonadotropin release to achieve gonadal differentiation in black porgy. Future studies may aim at investigating the cell localization and cell number of brain gnrhl neurons, pituitary gnrhr and gonadal gonadotropin receptors in relation to the activation of brain-pituitary-gonadal axis during gonadal sex differentiation by in situ hybridization or immunohistochemistry.

\subsection{Estradiol positive feedback on brain aromatase, and pituitary gonadotropins}

E2 exerted positive feedback on brain aromatase gene expression in the anterior brain in the present study, and this result was in agreement with our previous study at the time of gonadal differentiation (Lin et al., 2016). We also observed this stimulatory effect during testicular development. A local upregulation of E2 production via an autoregulatory loop through nuclear estrogen receptors and an ERE (estrogen response element) within the promoter region of the cyp19alb gene has been reported in various teleost species 

gonadal differentiation, this upregulation may enhance the local production of E2 and E2-regulated neurogenesis in the brain. During the period of testicular development, this upregulation may in addition enhance the E2-mediated feedback exerted by aromatizable androgen (testosterone) produced peripherally by the testis.

Teleost brain aromatase presented in radial glial cells, and distributed in brain and pituitary. Expression of Cyp19a1b was found in the pituitary of Japanese eel, tilapia, madaka, killifish, and ricefield eel by immunohistochemistry or in situ hybridization (Dong and Willett, 2008; Fontaine et al., 2019; Jeng et al., 2012b; Kitahashi et al., 2007; Zhang et al., 2014). Similar increased expression patterns of pituitary cyp19alb and $f s h b$ were found in roach at the onset of gametogenesis (Trubiroha et al., 2012). The administration of E2 stimulated pituitary $l \mathrm{hb}$ expression in adult sablefish and ricefield eel (Guzman et al., 2018; Zhang et al., 2014). Colocalized expression of Cyp19a1b and Lhb in pituitary was determined by immunostaining in female ricefield eel, and the colocalization frequency and immunoreactivity increased during vitellogenesis towards maturation (Zhang et al., 2014). These data suggest a role of pituitary Cyp19a1b involved in Gth regulation in teleost gametogenesis and maturation.

Treatment of E2 increased cyp19alb transcripts in the brain, but not in the pituitary cyp19alb of grey mullet (Nocillado et al., 2007). In Japanese eel, E2 and CPH (catfish pituitary homogenates) induced aromatase gene expression in the brain but not in the pituitary (Jeng et al., 2012a). Gene expression of cyp19alb showed different expression and regulation patterns between brain and pituitary of black porgy. The expression of brain cyp 19alb but not pituitary cyp19alb reached to a peak level during gonadal differentiation period and higher cyp19alb levels in the brain were observed during testicular development. Pituitary cyp19alb was not strongly regulated by E2 during testicular development as compared to the effects of E2 in the brain cyp19a1b. These results indicate the different regulation mechanism of cyp19alb between brain and pituitary. Correlated expression pattern of brain cyp19alb and pituitary gths was found during testicular development.

A stimulatory effect on gonadotropin subunit transcript levels by E2 was observed in this study. Pituitary $f s h b$ and $l h b$ increased significantly at all sampling times, including the periods of both gonadal differentiation and testicular development. Fshb showed a stronger response to E2 than did $l h b$. In previous studies in black porgy, radioimmunoassays for $\mathrm{Lh}$ revealed a positive effect of E2 treatment on Lh levels in the pituitary and plasma (Du et al., 2001; Lee et al., 2000; Yen et al., 2002), but no studies had investigated Fsh. The strong stimulatory effect of E2 on gonadotropin subunit transcript levels indicates positive feedback of sex steroids on the gonadotropic axis, a process that may contribute to increased expression during testicular development. E2 significantly stimulated Lh content in the pituitary and plasma, and a GnRH antagonist prevented the E2 stimulation of Lh 
release in 2-yr-old male adult black porgy, further demonstrating that the effect of E2 on Lh was mediated by Gnrh (Du et al., 2001; Lee et al., 2000; Yen et al., 2002). The increase in gonadotropin transcript levels may also result from a direct effect of E2 via the interaction of nuclear estrogen receptors and EREs within the promoter region of the gonadotropin subunit genes. EREs have been found in 5' gene-flanking regions of $f s h b$ and $l h b$ of fish, including Chinook salmon and Nile tilapia (Shupnik and Rosenzweig, 1991; Yaron et al., 2001). Future studies will aim to characterize the promoter regions of the $f s h b$ and $l h b$ genes in black porgy.

For the E2 effect on gonadotropin receptors, E2 decreased gene expressions of $f s h r$ and lhcgr in gonads. In previous study, higher gthr gene expression in testis than in ovary was observed in 1+- and 2+-yr-old black porgy (Du et al., 2005; Wu et al., 2016). E2 induced the development of ovarian tissue in protandrous black porgy (Wu et al., 2008a) which may cause the decrease of $g t h r$ transcript levels in gonads as shown in this study.

\subsection{Regulation of gnrhr in pituitary}

In black porgy, an increase in the pituitary expression of gnrhrl was found during sexual maturation in 2+-yr-old fish (Lin et al., 2010). E2 increased pituitary gnrhrl transcription levels during gonadal differentiation and during testicular development at 300 dah (Dec) in this study. Similar stimulation of E2 on pituitary gnrhrl also observed in 2+-yr-old black porgy, both in vivo and in vitro (Lin et al., 2010). Previous studies showed a positive effect of E2 on Lh release in black porgy (Du et al., 2001; Lee et al., 2000; Yen et al., 2002), thus the increase of gnrhrl expression by E2 probably further potentiate the endogeous GnRH action in stimulating pituitary Lh release. In contrast to the positive effects of E2 on pituitary gonadotropin and gnrhrl expression (Fig. 7), there was no effect of E2 on brain gnrhl expression during gonadal differentiation or during testicular development (Fig. 8).

\subsection{Estradiol-independent activation of gnrh1 during gonadal differentiation}

During gonadal differentiation in black porgy, a peak in neurosteroidogenesis and neurogenesis was found in the brain (Tomy et al., 2009; Tomy et al., 2007; Wu et al., 2010). We previously demonstrated that this peak was E2-dependent by applying exogenous E2 or aromatase inhibitor (Lin et al., 2016). E2-dependent mechanisms are thus involved in brain activation, including neurosteroidogenesis, the expression and activity of related genes (star, cyp19alb, nuclear estrogen receptors, aromatase activity), and neurogenesis (Pcna immunostaining, brain cell marker genes blbp and $b d n f$ ) during the period of gonadal differentiation in black porgy.

Unlike the E2-dependent genes that we examined in previous reports, E2 showed no significant effect on gnrhl expression. The E2 effects on gnrhl transcript levels were 
632 further confirmed by AI treatment, no significant changes were found between the control 633 and the AI- or E2-treated groups. The peaked expression of gnrhl during gonadal 634 differentiation was not affected by E2 or AI. Our study indicates that the peak of gnrhl 635 expression during the gonadal differentiation period was not induced by E2 and therefore 636 was not directly related to the peak of neurosteroidogenesis during this period in black 637 porgy.

638 In conclusion, some activation of the gonadotropic axis in black porgy occurs during 639 the gonadal differentiation period, as indicated by the peak expression of gnrhl and gnrhrl, 640 similar to that observed later during testicular development. This early activation may be 641 involved in the control of gonadal differentiation. The activation of gnrhl expression is 642 E2-independent and thus not directly related to the E2-dependent peak in brain 643 neurosteroidogenesis and neurogenesis previously reported during the period of gonadal 644 differentiation. Both E2-independent and E2-dependent mechanisms are thus involved in 645 the peak expression of various genes in the brain of black porgy at the time of gonadal 646 differentiation.

647

648

649 Acknowledgements

650 This work was supported by the Ministry of Science and Technology [MOST 651 105-2313-B-019-008-MY3] and the Center of Excellence for the Oceans, National Taiwan 652 Ocean University from The Featured Areas Research Center Program within the framework 653 of the Higher Education Sprout Project by the Ministry of Education (MOE) in Taiwan. 
Amano, M., Urano, A., Aida, K., 1997. Distribution and function of gonadotropin-releasing hormone $(\mathrm{GnRH})$ in the teleost brain. Zoolog Sci 14, 1-11.

Balthazart, J., Ball, G.F., 1998. New insights into the regulation and function of brain estrogen synthase (aromatase). Trends Neurosci 21, 243-249.

661

662

663

664

665

666

667

668

669

670

671

672

673

674

675

676

677

678

679

680

681

682

683

684

685

686

687

688

689

690

691

692

693

Breton, T.S., DiMaggio, M.A., Sower, S.A., Berlinsky, D.L., 2015. Brain aromatase (cyp19a1b) and gonadotropin releasing hormone (gnrh2 and gnrh3) expression during reproductive development and sex change in black sea bass (Centropristis striata). Comp Biochem Physiol A Mol Integr Physiol 181, 45-53.

Chang, C.F., Lee, M.F., Chen, G.R., 1994. Estradiol-17 $\beta$ associated with the sex reversal in protandrous black porgy, Acanthopagrus schlegeli. J Exp Zool 268, 53-58.

Chang, C.F., Yueh, W.S., 1990. Annual cycle of gonadal histology and steroid profiles in the juvenile males and adult females of the protandrous black porgy, Acanthopagrus schlegeli. Aquaculture 91, 179-196.

Chang, C.F., Yueh, W.S., Lee, M.F., 1991. Effects of LHRH-A and HCG on the steroid profiles of bisexual and mature male and female protandrous black porgy, Acanthopagrus schlegeli. Aquaculture 92, 83-92.

Diotel, N., Do Rego, J.L., Anglade, I., Vaillant, C., Pellegrini, E., Gueguen, M.M., Mironov, S., Vaudry, H., Kah, O., 2011. Activity and expression of steroidogenic enzymes in the brain of adult zebrafish. Eur J Neurosci 34, 45-56.

Diotel, N., Le Page, Y., Mouriec, K., Tong, S.K., Pellegrini, E., Vaillant, C., Anglade, I., Brion, F., Pakdel, F., Chung, B.C., Kah, O., 2010. Aromatase in the brain of teleost fish: expression, regulation and putative functions. Front Neuroendocrinol 31, 172-192.

Dong, W., Willett, K.L., 2008. Local expression of CYP19A1 and CYP19A2 in developing and adult killifish (Fundulus heteroclitus). Gen Comp Endocrinol 155, 307-317.

Du, J.L., Lee, C.Y., Tacon, P., Lee, Y.H., Yen, F.P., Tanaka, H., Dufour, S., Chang, C.F., 2001. Estradiol-17beta stimulates gonadotropin II expression and release in the protandrous male black porgy Acanthopagrus schlegeli Bleeker: a possible role in sex change. Gen Comp Endocrinol 121, 135-145.

Du, J.L., Lee, Y.H., Yueh, W.S., Chang, C.F., 2005. Seasonal profiles of brain and pituitary gonadotropin-releasing hormone and plasma luteinizing hormone in relation to sex change of protandrous black porgy, Acanthopagrus schlegeli. Biol Reprod 72, 922-931.

Fontaine, R., Ager-Wick, E., Hodne, K., Weltzien, F.A., 2019. Plasticity of Lh cells caused by cell proliferation and recruitment of existing cells. J Endocrinol 240, 361-377.

Forlano, P.M., Deitcher, D.L., Myers, D.A., Bass, A.H., 2001. Anatomical distribution and cellular basis for high levels of aromatase activity in the brain of teleost fish: 
aromatase enzyme and mRNA expression identify glia as source. J Neurosci 21, 8943-8955.

Guzman, J.M., Luckenbach, J.A., da Silva, D.A.M., Hayman, E.S., Ylitalo, G.M., Goetz, F.W., Swanson, P., 2018. Seasonal variation of pituitary gonadotropin subunit, brain-type aromatase and sex steroid receptor mRNAs, and plasma steroids during gametogenesis in wild sablefish. Comp Biochem Physiol A Mol Integr Physiol 219-220, 48-57.

He, C.L., Du, J.L., Wu, G.C., Lee, Y.H., Sun, L.T., Chang, C.F., 2003. Differential Dmrt1 transcripts in gonads of the protandrous black porgy, Acanthopagrus schlegeli. Cytogenet Genome Res 101, 309-313.

Jeng, S.R., Pasquier, J., Yueh, W.S., Chen, G.R., Lee, Y.H., Dufour, S., Chang, C.F., 2012a. Differential regulation of the expression of cytochrome P450 aromatase, estrogen and androgen receptor subtypes in the brain-pituitary-ovarian axis of the Japanese eel (Anguilla japonica) reveals steroid dependent and independent mechanisms. Gen Comp Endocrinol 175, 163-172.

Jeng, S.R., Yueh, W.S., Pen, Y.T., Gueguen, M.M., Pasquier, J., Dufour, S., Chang, C.F., Kah, O., 2012b. Expression of aromatase in radial glial cells in the brain of the Japanese eel provides insight into the evolution of the cyp191a gene in Actinopterygians. PLoS One 7, e44750.

Kitahashi, T., Ogawa, S., Soga, T., Sakuma, Y., Parhar, I., 2007. Sexual maturation modulates expression of nuclear receptor types in laser-captured single cells of the cichlid (Oreochromis niloticus) pituitary. Endocrinology 148, 5822-5830.

Le Page, Y., Vosges, M., Servili, A., Brion, F., Kah, O., 2011. Neuroendocrine effects of endocrine disruptors in teleost fish. J Toxicol Environ Health B Crit Rev 14, 370-386.

Lee, M.F., Huang, J.D., Chang, C.F., 2008. Development of ovarian tissue and female germ cells in the protandrous black porgy, Acanthopagrus schlegeli Perciformes, Sparidae. . Zoological Studies 47, 302-316.

Lee, Y.H., Du, J.L., Yueh, W.S., Lee, F.Y., Tanaka, H., Chang, C.F., 1999. 17ß-Estradiol, but not testosterone stimulates gonadotropin II concentrations in the protandrous black porgy, Acanthopagrus schlegeli Bleeker. Fish Physiol Biochem 21, 345-351.

Lee, Y.H., Du, J.L., Yueh, W.S., Lin, B.Y., Huang, J.D., Lee, C.Y., Lee, M.F., Lau, E.L., Lee, F.Y., Morrey, C., Nagahama, Y., Chang, C.F., 2001. Sex change in the protandrous black porgy, Acanthopagrus schlegeli: a review in gonadal development, estradiol, estrogen receptor, aromatase activity and gonadotropin. J Exp Zool 290, 715-726.

Lee, Y.H., Lee, F.Y., Yueh, W.S., Tacon, P., Du, J.L., Chang, C.N., Jeng, S.R., Tanaka, H., Chang, C.F., 2000. Profiles of gonadal development, sex steroids, aromatase activity, and gonadotropin II in the controlled sex change of protandrous black porgy, 
Acanthopagrus schlegeli Bleeker. Gen Comp Endocrinol 119, 111-120.

733

734

735

736

737

738

739

740

741

742

743

744

745

746

747

748

749

750

751

752

753

754

755

756

757

758

759

760

761

762

763

764

765

766

767

768

769 Lee, Y.H., Yueh, W.S., Du, J.L., Sun, L.T., Chang, C.F., 2002. Aromatase inhibitors block natural sex change and induce male function in the protandrous black porgy, Acanthopagrus schlegeli Bleeker: possible mechanism of natural sex change. Biol Reprod 66, 1749-1754.

Lin, C.J., Fan-Chiang, Y.C., Dufour, S., Chang, C.F., 2016. Activation of brain steroidogenesis and neurogenesis during the gonadal differentiation in protandrous black porgy, Acanthopagrus schlegelii. Dev Neurobiol 76, 121-136.

Lin, C.J., Wu, G.C., Lee, M.F., Lau, E.L., Dufour, S., Chang, C.F., 2010. Regulation of two forms of gonadotropin-releasing hormone receptor gene expression in the protandrous black porgy fish, Acanthopagrus schlegeli. Mol Cell Endocrinol 323, 137-146.

Menuet, A., Anglade, I., Le Guevel, R., Pellegrini, E., Pakdel, F., Kah, O., 2003. Distribution of aromatase mRNA and protein in the brain and pituitary of female rainbow trout: Comparison with estrogen receptor alpha. J Comp Neurol 462, 180-193.

Miranda, L.A., Strobl-Mazzulla, P.H., Strussmann, C.A., Parhar, I., Somoza, G.M., 2003. Gonadotropin-releasing hormone neuronal development during the sensitive period of temperature sex determination in the pejerrey fish, Odontesthes bonariensis. Gen Comp Endocrinol 132, 444-453.

Miranda, L.A., Strussmann, C.A., Somoza, G.M., 2001. Immunocytochemical identification of $\mathrm{GtH} 1$ and $\mathrm{GtH} 2$ cells during the temperature-sensitive period for sex determination in pejerrey, Odontesthes bonariensis. Gen Comp Endocrinol 124, 45-52.

Moles, G., Carrillo, M., Mananos, E., Mylonas, C.C., Zanuy, S., 2007. Temporal profile of brain and pituitary GnRHs, GnRH-R and gonadotropin mRNA expression and content during early development in European sea bass (Dicentrarchus labrax L.). Gen Comp Endocrinol 150, 75-86.

Munakata, A., Kobayashi, M., 2010. Endocrine control of sexual behavior in teleost fish. Gen Comp Endocrinol 165, 456-468.

Nocillado, J.N., Elizur, A., Avitan, A., Carrick, F., Levavi-Sivan, B., 2007. Cytochrome P450 aromatase in grey mullet: cDNA and promoter isolation; brain, pituitary and ovarian expression during puberty. Mol Cell Endocrinol 263, 65-78.

Pellegrini, E., Mouriec, K., Anglade, I., Menuet, A., Le Page, Y., Gueguen, M.M., Marmignon, M.H., Brion, F., Pakdel, F., Kah, O., 2007. Identification of aromatase-positive radial glial cells as progenitor cells in the ventricular layer of the forebrain in zebrafish. J Comp Neurol 501, 150-167.

Ramallo, M.R., Morandini, L., Birba, A., Somoza, G.M., Pandolfi, M., 2017. From molecule 
to behavior: Brain aromatase (cyp19a1b) characterization, expression analysis and its relation with social status and male agonistic behavior in a Neotropical cichlid fish. Horm Behav 89, 176-188.

Rodriguez, L., Carrillo, M., Sorbera, L.A., Soubrier, M.A., Mananos, E., Holland, M.C., Zohar, Y., Zanuy, S., 2000. Pituitary levels of three forms of GnRH in the male European sea bass (Dicentrarchus labrax, L.) during sex differentiation and first spawning season. Gen Comp Endocrinol 120, 67-74.

Senthilkumaran, B., Sudhakumari, C.C., Mamta, S.K., Raghuveer, K., Swapna, I., Murugananthkumar, R., 2015. "Brain sex differentiation" in teleosts: Emerging concepts with potential biomarkers. Gen Comp Endocrinol 220, 33-40.

Shupnik, M.A., Rosenzweig, B.A., 1991. Identification of an estrogen-responsive element in the rat LH beta gene. DNA-estrogen receptor interactions and functional analysis. J Biol Chem 266, 17084-17091.

Somoza, G.M., Miranda, L.A., Guilgur, L.G., Strobl-Mazzulla, P.H., 2006. Characterization of the brain-pituitary axis in pejerrey Odontesthes bonariensis. Biocell 30, 89-95.

Strobl-Mazzulla, P.H., Lethimonier, C., Gueguen, M.M., Karube, M., Fernandino, J.I., Yoshizaki, G., Patino, R., Strussmann, C.A., Kah, O., Somoza, G.M., 2008. Brain aromatase (Cyp19A2) and estrogen receptors, in larvae and adult pejerrey fish Odontesthes bonariensis: Neuroanatomical and functional relations. Gen Comp Endocrinol 158, 191-201.

Strobl-Mazzulla, P.H., Moncaut, N.P., Lopez, G.C., Miranda, L.A., Canario, A.V., Somoza, G.M., 2005. Brain aromatase from pejerrey fish (Odontesthes bonariensis): cDNA cloning, tissue expression, and immunohistochemical localization. Gen Comp Endocrinol 143, 21-32.

Swapna, I., Sudhakumari, C.C., Sakai, F., Sreenivasulu, G., Kobayashi, T., Kagawa, H., Nagahama, Y., Senthilkumaran, B., 2008. Seabream GnRH immunoreactivity in brain and pituitary of XX and XY Nile tilapia, Oreochromis niloticus during early development. J Exp Zool A Ecol Genet Physiol 309, 419-426.

Tomy, S., Wu, G.C., Huang, H.R., Chang, C.F., 2009. Age-dependent differential expression of genes involved in steroid signalling pathway in the brain of protandrous black porgy, Acanthopagrus schlegeli. Dev Neurobiol 69, 299-313.

Tomy, S., Wu, G.C., Huang, H.R., Dufour, S., Chang, C.F., 2007. Developmental expression of key steroidogenic enzymes in the brain of protandrous black porgy fish, Acanthopagrus schlegeli. J Neuroendocrinol 19, 643-655.

Trubiroha, A., Kroupova, H., Wuertz, S., Kloas, W., 2012. Up-regulation of gonadotropin mRNA-expression at the onset of gametogenesis in the roach (Rutilus rutilus): evidence for an important role of brain-type aromatase (cyp19a1b) in the pituitary. Gen Comp Endocrinol 178, 529-538. 
Vizziano-Cantonnet, D., Anglade, I., Pellegrini, E., Gueguen, M.M., Fostier, A., Guiguen, Y., Kah, O., 2011. Sexual dimorphism in the brain aromatase expression and activity, and in the central expression of other steroidogenic enzymes during the period of sex differentiation in monosex rainbow trout populations. Gen Comp Endocrinol 170, 346-355.

Wu, G.C., Li, H.W., Huang, C.H., Lin, H.J., Lin, C.J., Chang, C.F., 2016. The testis is a primary factor that contributes to epigenetic modifications in the ovaries of the protandrous black porgy, Acanthopagrus schlegelii. Biol Reprod 94, 132.

Wu, G.C., Tomy, S., Chang, C.F., 2008a. The expression of nr0b1 and nr5a4 during gonad development and sex change in protandrous black porgy fish, Acanthopagrus schlegeli. Biol Reprod 78, 200-210.

Wu, G.C., Tomy, S., Lee, M.F., Lee, Y.H., Yueh, W.S., Lin, C.J., Lau, E.L., Chang, C.F., 2010. Sex differentiation and sex change in the protandrous black porgy, Acanthopagrus schlegeli. Gen Comp Endocrinol 167, 417-421.

Wu, G.C., Tomy, S., Nakamura, M., Chang, C.F., 2008b. Dual roles of cyp19a1a in gonadal sex differentiation and development in the protandrous black porgy, Acanthopagrus schlegeli. Biol Reprod 79, 1111-1120.

Yan, H., Ijiri, S., Wu, Q., Kobayashi, T., Li, S., Nakaseko, T., Adachi, S., Nagahama, Y., 2012. Expression patterns of gonadotropin hormones and their receptors during early sexual differentiation in Nile tilapia Oreochromis niloticus. Biol Reprod 87, 116.

Yaron, Z., Gur, G., Melamed, P., Rosenfeld, H., Levavi-Sivan, B., Elizur, A., 2001. Regulation of gonadotropin subunit genes in tilapia. Comp Biochem Physiol B Biochem Mol Biol 129, 489-502.

Yen, F.P., Lee, Y.H., He, C.L., Huang, J.D., Sun, L.T., Dufour, S., Chang, C.F., 2002. Estradiol-17beta triggers luteinizing hormone release in the protandrous black porgy (Acanthopagrus schlegeli Bleeker) through multiple interactions with gonadotropin-releasing hormone control. Biol Reprod 66, 251-257.

Zhang, S., Zhang, Y., Chen, W., Wu, Y., Ge, W., Zhang, L., Zhang, W., 2014. Aromatase (Cyp19a1b) in the pituitary is dynamically involved in the upregulation of lhb but not fshb in the vitellogenic female ricefield eel Monopterus albus. Endocrinology $155,4531-4541$.

Zhang, Z., Lau, S.W., Zhang, L., Ge, W., 2015a. Disruption of Zebrafish Follicle-Stimulating Hormone Receptor (fshr) But Not Luteinizing Hormone Receptor (lhcgr) Gene by TALEN Leads to Failed Follicle Activation in Females Followed by Sexual Reversal to Males. Endocrinology 156, 3747-3762.

Zhang, Z., Zhu, B., Ge, W., 2015b. Genetic analysis of zebrafish gonadotropin (FSH and LH) functions by TALEN-mediated gene disruption. Mol Endocrinol 29, 76-98. 
848 lateral views. Brain tissues were collected and dissected into two parts, the telencephalon 849 (TE) and di-/mesencephalon (DME), for analysis in real-time PCR. TE includes both the 850 telencephalon and olfactory bulbs; DME includes the hypothalamus, preoptic area and 851 thalamus. HB, hindbrain; Hyp, hypothalamus; MO, medulla oblongata; OB, olfactory bulb; 852 OC, optic chiasm; OT, optic tectum; POA, preoptic area; SV, saccus vasculosus; Tel, telencephalon; Thal, thalamus; VCe, valvula cerebelli.

Figure 2. Characterization of gonadal features during the periods of gonadal differentiation (90, 120 and 150 dah) and of testicular development (180 and 210 dah) in control and estradiol (E2)-treated fish. Transverse sections $(6 \mu \mathrm{m})$ of gonad tissues were stained by hematoxylin-eosin (A1-G1) and immunohistochemical staining of Pcna, a cell proliferation marker (A2-G2). High-magnification images are shown in F1'-G1' (H\&E staining) and A2'-G2' (Pcna-immunostaining). The arrow indicates spermatogonia, and the dashed circle indicates the lobular structure of the testicular cyst in control fish. For E2-treated fish, the arrowhead indicates primary oocytes and the open arrowhead indicates oogonia.

864

Figure 3. Gene expression profiles in the pituitary of black porgy at 90-300 dah, as determined by real-time PCR analysis. The relative gene expression levels of $f s h b, l h b$, gpa, gnrhrl and cyp19alb were analyzed during the sex differentiation period (90-150 dah) and testicular development period (180-300 dah). The transcript values of genes were calibrated with gapdh as an internal control and then normalized to the value of the pituitary at 90 dah, which was defined as 1 . The results are expressed as the mean \pm SEM $(n=4$ pools/group for pituitary with 10 individual pituitaries/pool for 90 to 150 dah or with 5 individual pituitaries/pool for 180 to 300 dah). Lowercase letters indicate significant differences $(P<0.05)$ in gene expression in the pituitary between groups according to one-way ANOVA followed by Duncan's test. porgy at 90-300 dah, as determined by real-time PCR analysis. The relative gene expression levels of gnrhl, gnrh2, gnrh3 and cyp19alb were analyzed during the sex differentiation period (90-150 dah) and testicular development period (180-300 dah). Based on their brain expression distribution, gnrhl was measured in telencephalon and di-/mesencephalon, gnrh2 in di-/mesencephalon, and gnrh3 in telencephalon. The transcript values of genes were calibrated with gapdh as an internal control and then normalized to the 
expressed as the mean \pm SEM ( $n=8$ individuals/group). Lowercase letters indicate significant differences $(P<0.05)$ in gene expression in different brain parts between groups according to one-way ANOVA followed by Duncan's test. determined by real-time PCR analysis. The relative gene expression of $f s h r$ and $l h c g r$ were analyzed during sex differentiation period (90-150 dah) and testicular development period (180-300 dah). The transcript values of gene were calibrated with gapdh as an internal control and then normalized to the value of the gonad at 90 dah, which was defined as 1 . The results are expressed as the mean \pm SEM $(n=3$ pools/group for gonad with 8 individual gonads/pool for 90 to $150 \mathrm{dah}, \mathrm{n}=4$ pools/group for gonad with 4 individual gonads/pool for 180 dah, $\mathrm{n}=5$ pools/group for gonad with 2 individual gonads/pool for 210 and 240 dah, $\mathrm{n}=10$ individual gonads/group for 300 dah). Lowercase letters indicate significant difference $(P<0.05)$ in gene expression in gonad between groups according to the one-way ANOVA followed by Duncan's test.

Figure 6. Real-time PCR analysis of cyp19a1b in the telencephalon, di-/mesencephalon and pituitary of control fish or estradiol (E2)-treated fish. E2-treated fish were fed with an estradiol diet (6 mg/kg feed) from 90 dah. Control and E2-treated samples were collected during the sex differentiation period (90-150 dah) and testicular development period (180-300 dah). The transcript values of cyp19alb were calibrated with gapdh as an internal control and then normalized to the value of 90 dah control fish, which was defined as 1 . The results are expressed as the mean \pm SEM ( $n=8$ individuals/group for telencephalon and di-/mesencephalon; $\mathrm{n}=4$ pools/group for pituitary with 10 individual pituitaries/pool for 90 to 150 dah, or with 5 individual pituitaries/pool for 180 to 300 dah). Asterisks indicate significant differences $(P<0.05)$ between control and E2-treated groups at each age, according to Student's $t$-test.

911

912 Figure 7. Real-time PCR analysis of $\boldsymbol{f} \boldsymbol{s h b}, \boldsymbol{l h b}$, gpa and gnrhrl in the pituitary of 913 control fish or estradiol (E2)-treated fish. E2-treated fish were fed with an estradiol diet

914 (6 mg/kg feed) from 90 dah. Control and E2-treated samples were collected during the sex 915 differentiation period (90-150 dah) and the testicular development period (180-300 dah).

916 The transcript values of gene were calibrated with gapdh as an internal control and then 917 normalized to the value of 90 dah control fish, which was defined as 1 . The results are 918 expressed as the mean \pm SEM $(n=4$ pools/group for pituitary with 10 individual 919 pituitaries/pool for 90 to 150 dah or with 5 individual pituitaries/pool for 180 to 300 dah). 920 Asterisks indicate significant differences $(P<0.05)$ between control and E2-treated groups at each age, according to Student's $t$-test. 
923 Figure 8. Real-time PCR analysis of gnrh1, gnrh2 and gnrh3 in the telencephalon and

924 di-/mesencephalon of control fish or estradiol (E2)-treated fish. E2-treated fish were fed

925 with an estradiol diet $(6 \mathrm{mg} / \mathrm{kg}$ feed) from 90 dah. Control and E2-treated samples were

926 collected during the sex differentiation period (90-150 dah) and the testicular development

927 period (180-300 dah). The transcript values of gene were calibrated with gapdh as an

928 internal control and then normalized to the value of 90 dah control fish, which was defined

929 as 1 . The results are expressed as the mean \pm SEM ( $n=8$ individuals/group). Asterisks

930 indicate significant differences $(P<0.05)$ between control and E2-treated groups at each

931 age, according to Student's $t$-test.

932

933 Figure 9. Real-time PCR analysis of $\boldsymbol{f s h}$ and $\mathbf{l h c g r}$ in the gonad of control fish or

934 estradiol (E2)-treated fish. E2-treated fish were fed with an estradiol diet $(6 \mathrm{mg} / \mathrm{kg}$ feed $)$

935 from 90 dah. Control and E2-treated samples were collected during the testicular

936 development period (180-300 dah). The transcript values of gene were calibrated with

937 gapdh as an internal control and then normalized to the value of 180 dah control fish, which

938 was defined as 1 . The results are expressed as the mean \pm SEM $(n=4$ pools/group for

939 gonad with 4 individual gonads/pool for 180 dah, $\mathrm{n}=5$ pools/group for gonad with 2

940 individual gonads/pool for 210 and 240 dah, $\mathrm{n}=10$ individual gonads/group for 300 dah).

941 Asterisks indicate significant differences $(P<0.05)$ between control and E2-treated groups

942 at each age, according to Student's $t$-test.

943

944 Figure 10. Real-time PCR analysis of gnrh1 and cyp19a1b in the telencephalon and 945 di-/mesencephalon of control, estradiol (E2)-treated or aromatase inhibitor 946 (AI)-treated fish. E2- $(6 \mathrm{mg} / \mathrm{kg}$ feed) or AI- $(20 \mathrm{mg} / \mathrm{kg}$ feed $)$ treated fish were fed from 90 947 dah. Samples were collected during the sex differentiation period (90-150 dah). The 948 transcript values of gene were calibrated with gapdh as an internal control and then 949 normalized to the value of 90 dah control fish, which was defined as 1 . The results are 950 expressed as the mean \pm SEM ( $n=3$ individuals/group). Asterisks indicate significant 951 differences $(P<0.05)$ between control and treatment groups at each age, according to 952 Student's $t$-test.

953

954 
955 Supplemental figure legends

956 Supplemental Figure S1. Tissue distribution of black porgy cyp19a1b (682-bp)

957 detected by RT-PCR. Amplification of gapdh (451-bp) was used as an internal control. B,

958 brain; P, pituitary; H, heart; G, gill; HK, head kidney; K, kidney; L, liver; S, spleen; I,

959 intestine; M, muscle; SV, seminal vesicle; T, testis; O, ovary; N, negative control. Specific

960 primers for cyp19alb (forward: 5'- GGGAGGGGGATCATTTT -3'; reverse: 5'-

961 CAGGCTTTGACAATCAATGT -3') and gapdh (forward: 5'-

962 GCATCTTGCACGACTAACTGCCTGG -3'; reverse: 5'- CGGCGCCGGCATCGAAG -3')

963 were used.

964

965 Supplemental Figure S2. Specificity for qPCR primers. For the reason that the gene

966 sequences are highly conserved, the qPCR primer specificity was analyzed by PCR in gene

967 families: the pituitary glycoprotein hormone family $(f s h, l h b, g p a)$, the GnRH family

968 (gnrh1, gnrh2, gnrh3), and the G-protein coupled receptor 1 family $(f s h r, l h c g r)$. The genes'

969 plasmid DNA were used as templates in PCR reactions for 40 cycles with specific qPCR

970 primers for each gene. As shown in figure, each group of specific primers were subjected to

971 amplify with the corresponding plasmid DNA template. Therefore, the primer specificity is

972 confirmed and the genetic analysis in the real-time quantitative PCR system is specific and

973 independent. ntc, non-template control.

974

975 Supplemental Figure S3. Characteristics of different male germ cells. Black porgy

976 testes were collected and stained with hematoxylin-eosin or Pcna-immunohistochemical

977 staining. Oval-shaped germ cells were observed under a microscope. Germ cells were

978 identified as type A spermatogonia (SGA) in differentiated gonads. Late spermatogonia with

979 dark nuclei were identified as type B spermatogonia (SGB) in developmental testes. The

980 arrow indicates spermatogonia.

981 
Control fish

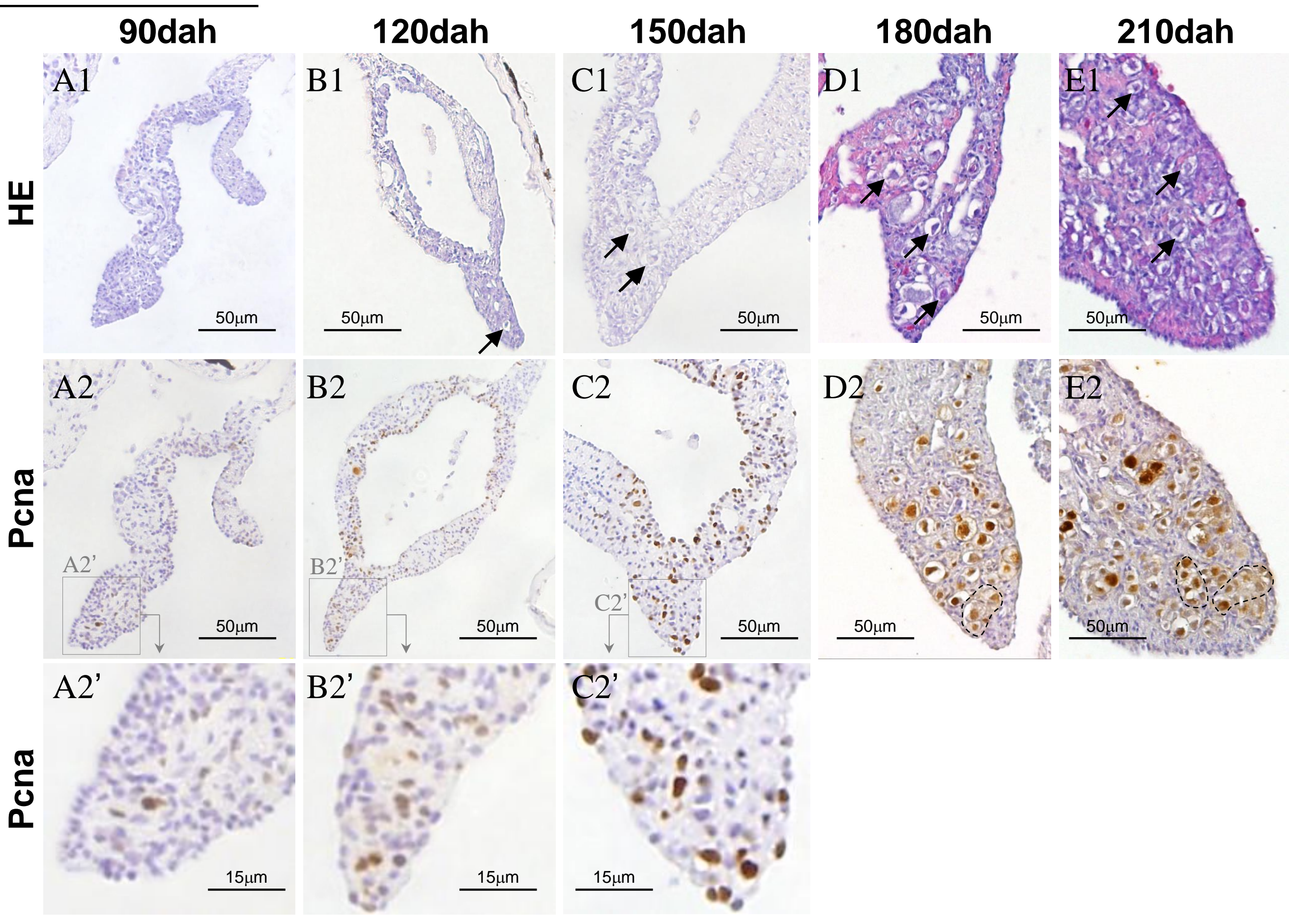

\section{E2-treated fish}

\section{Differentiation stage (150dah)}

E13

$\underset{I}{\Psi}$

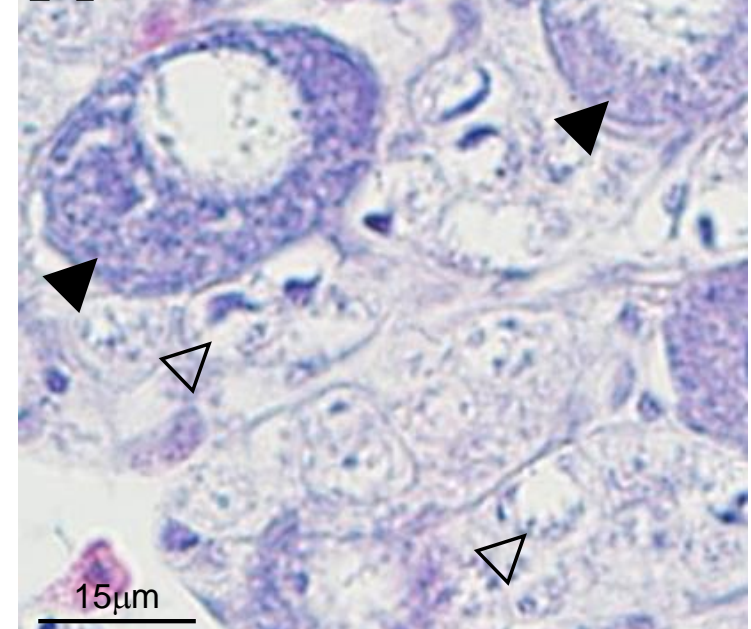

$100 \mu \mathrm{m}$
F2
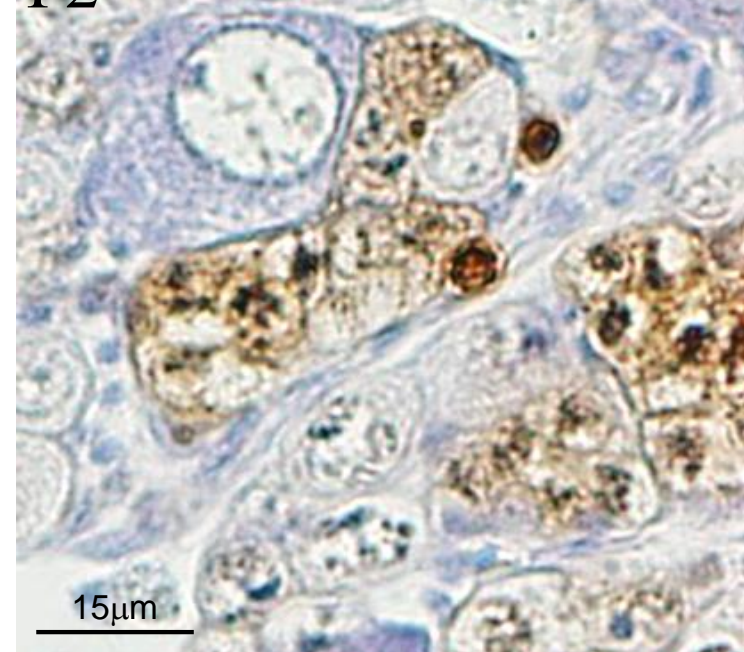

Development stage (180dah)
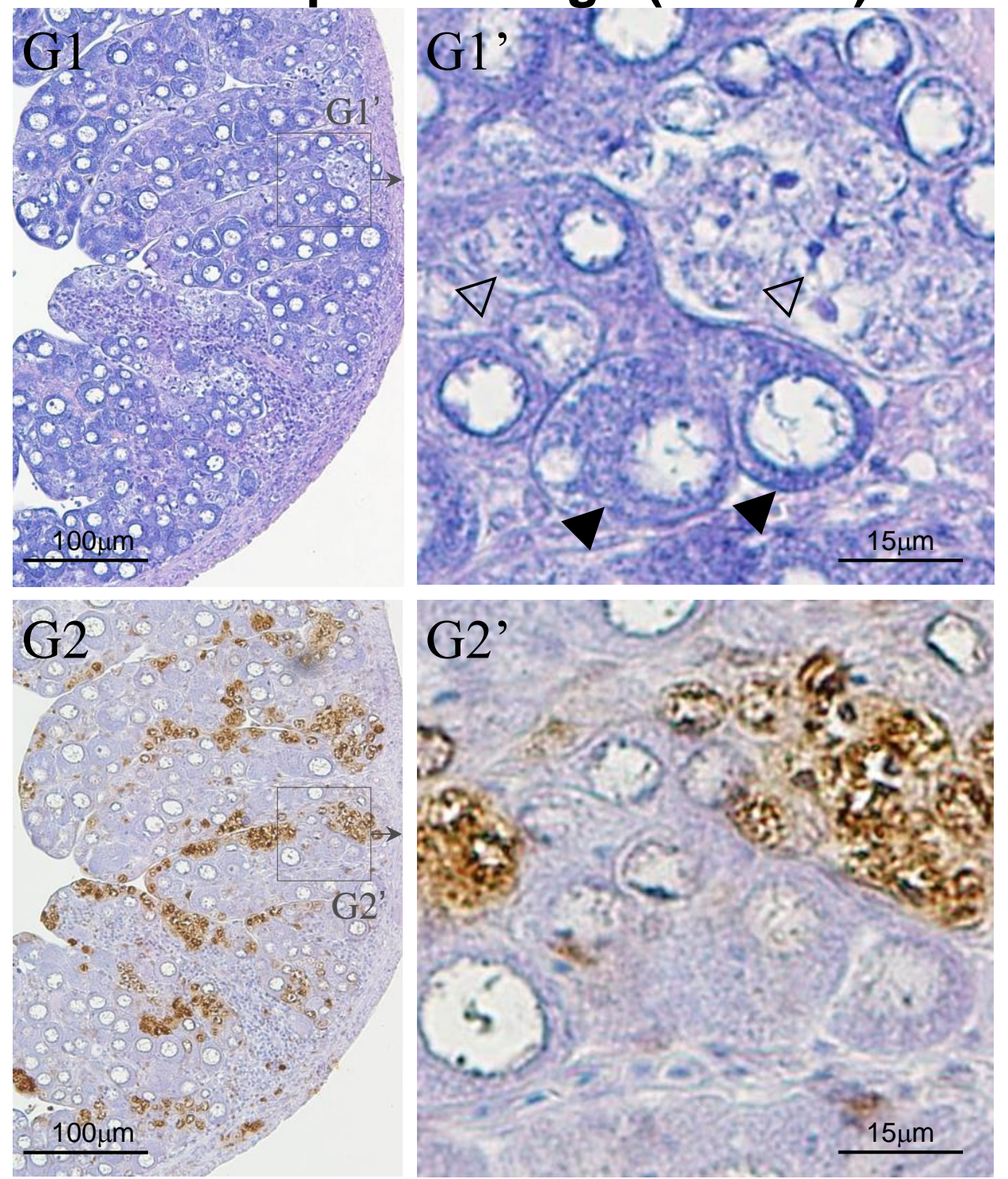

Figure 2 

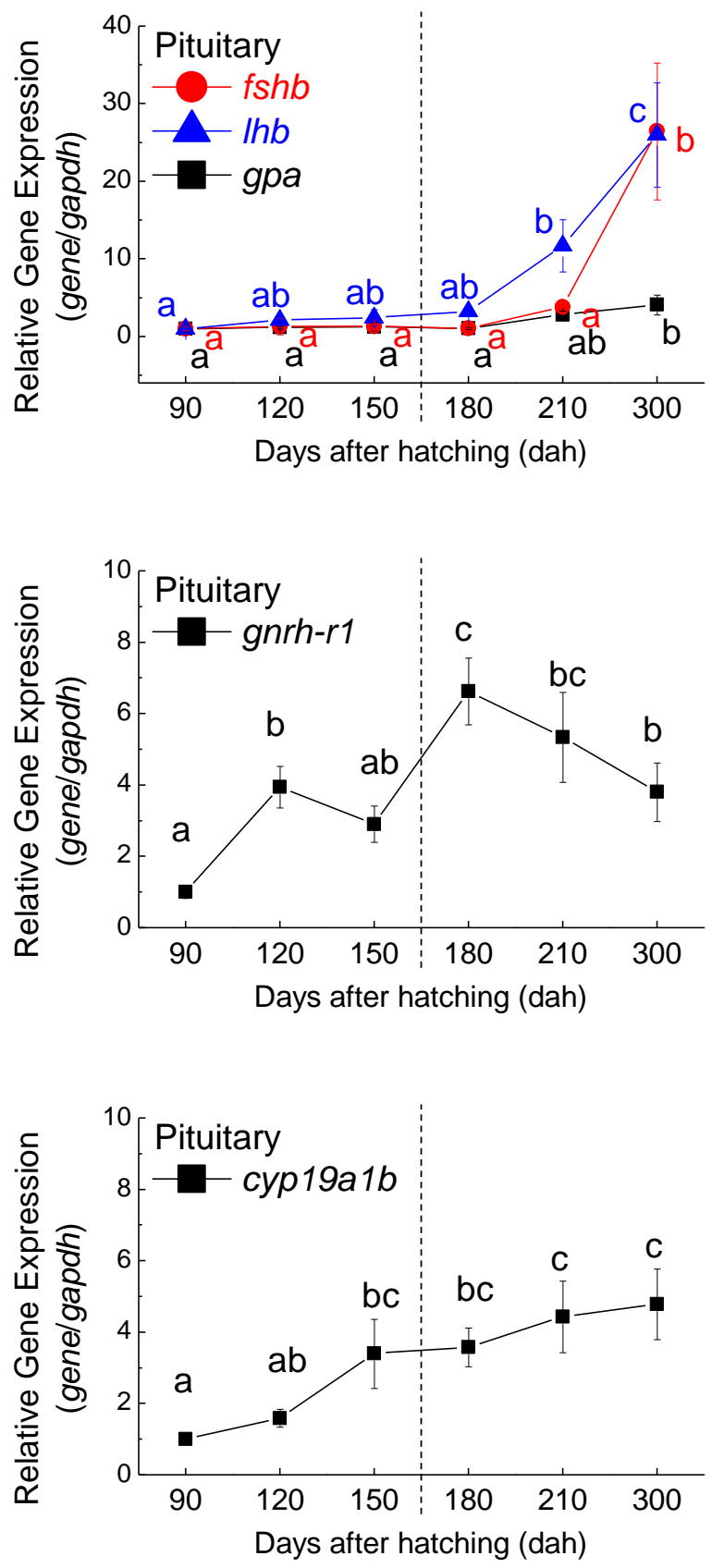

Figure 3 

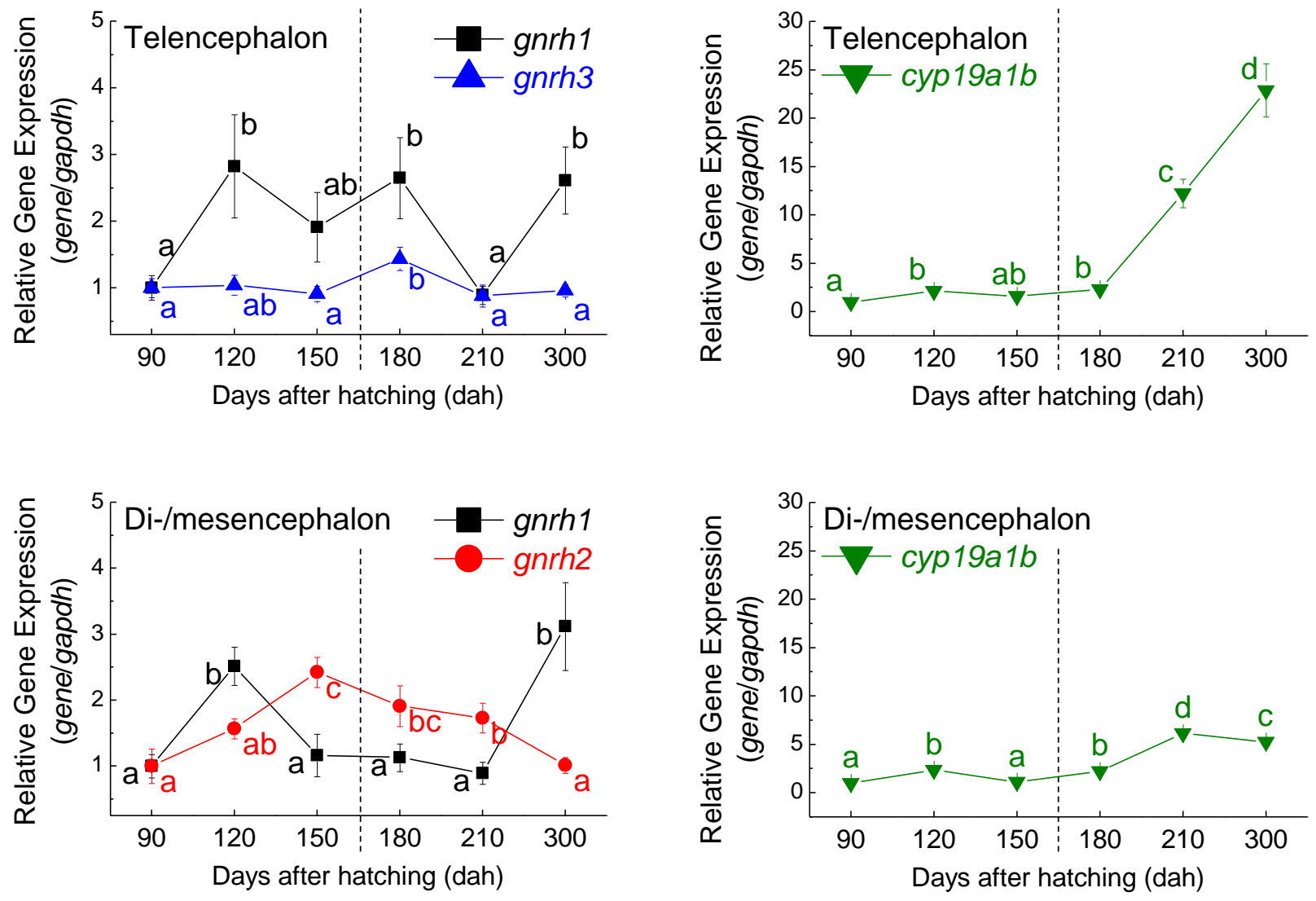

Figure 4 


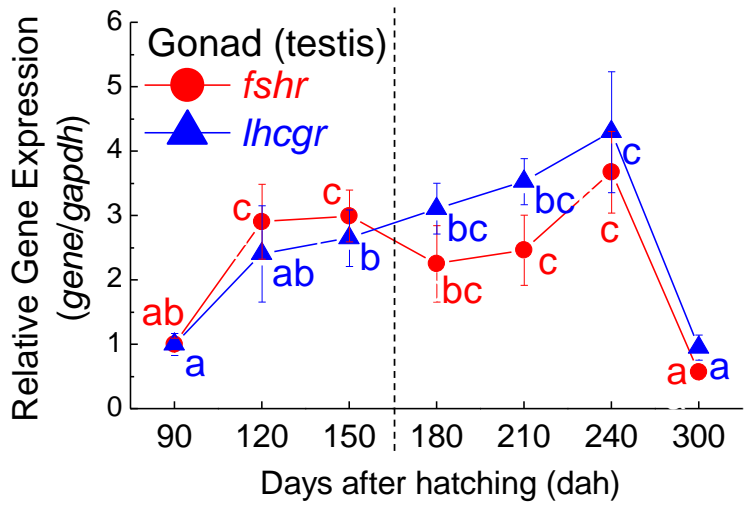

Figure 5 

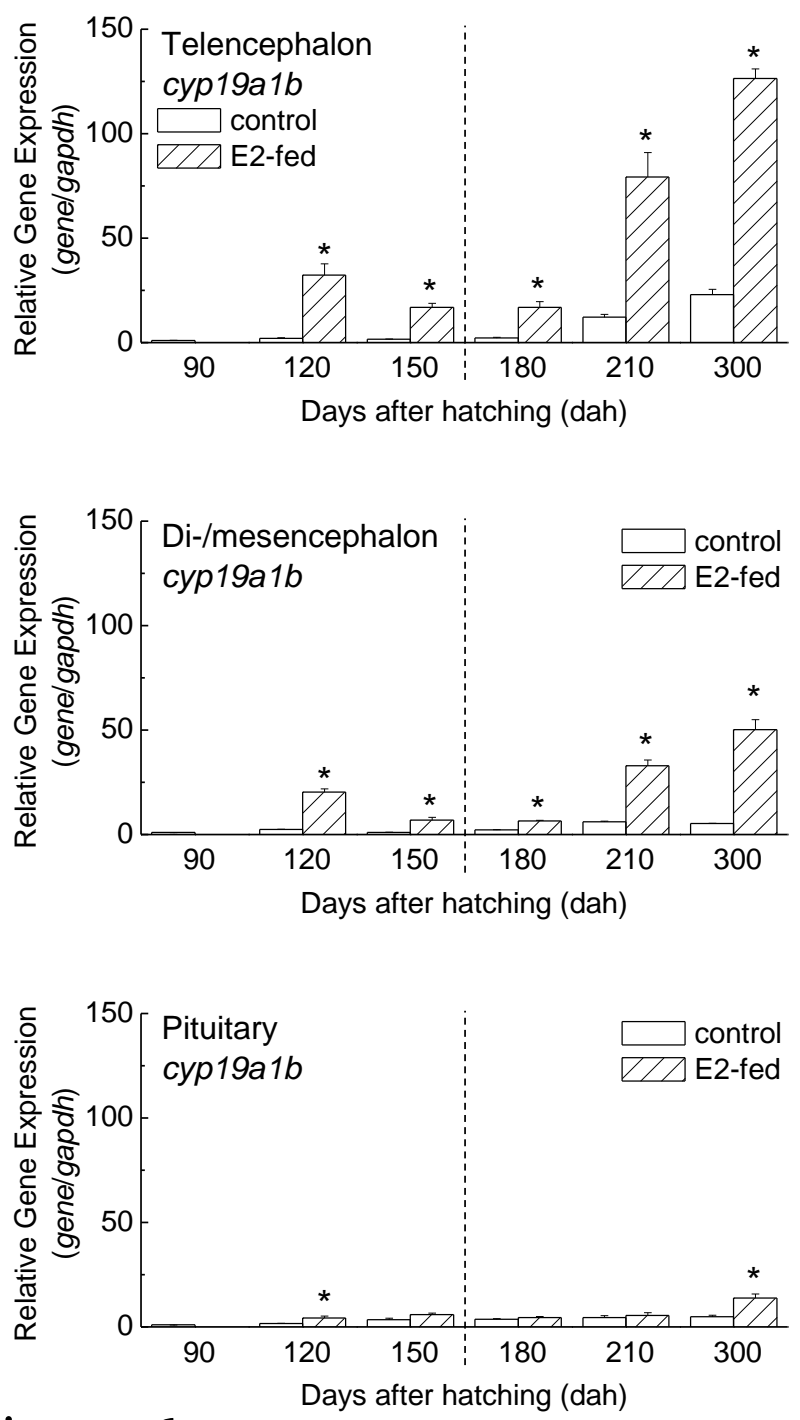

Figure 6 

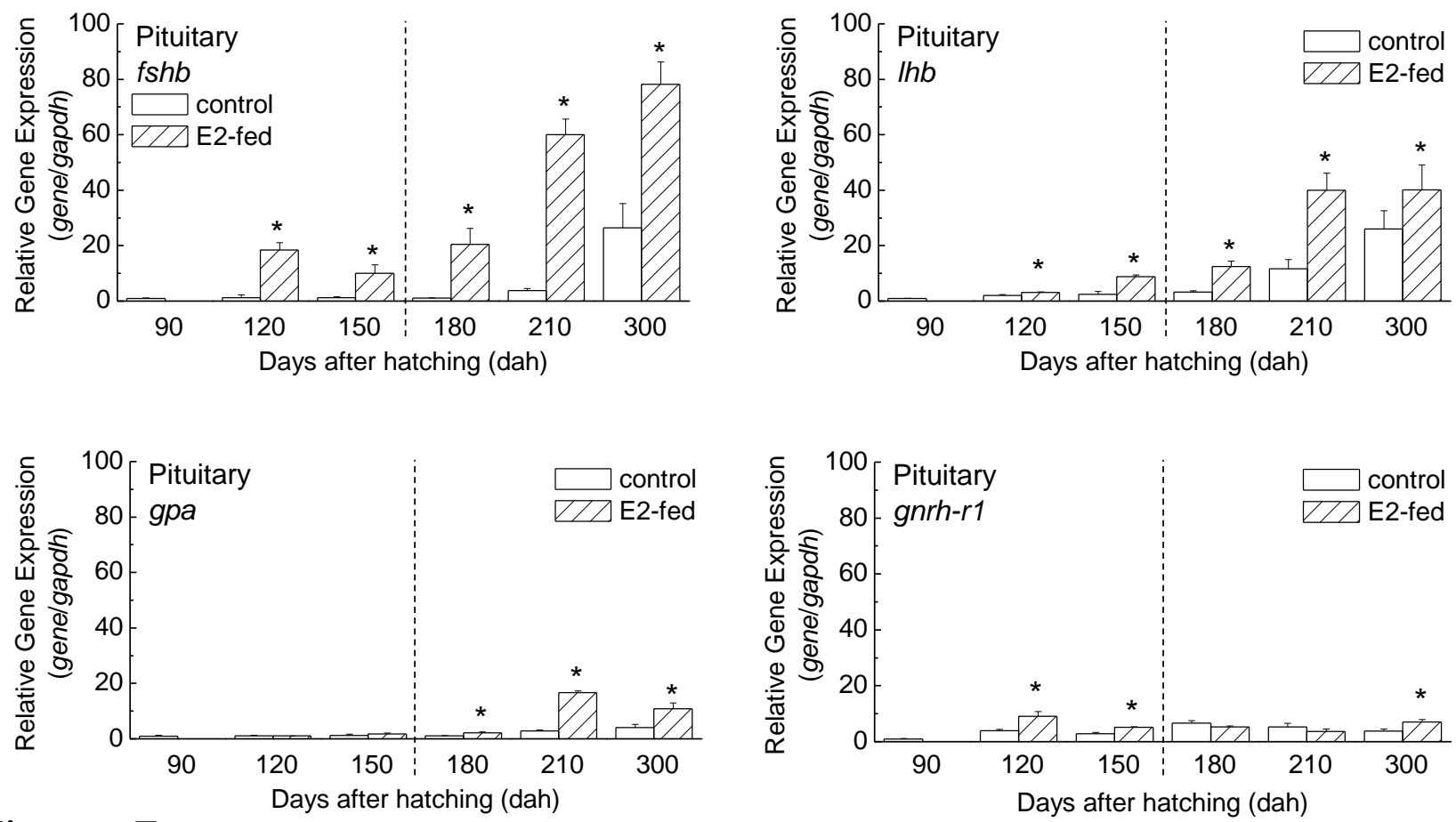

Figure 7 

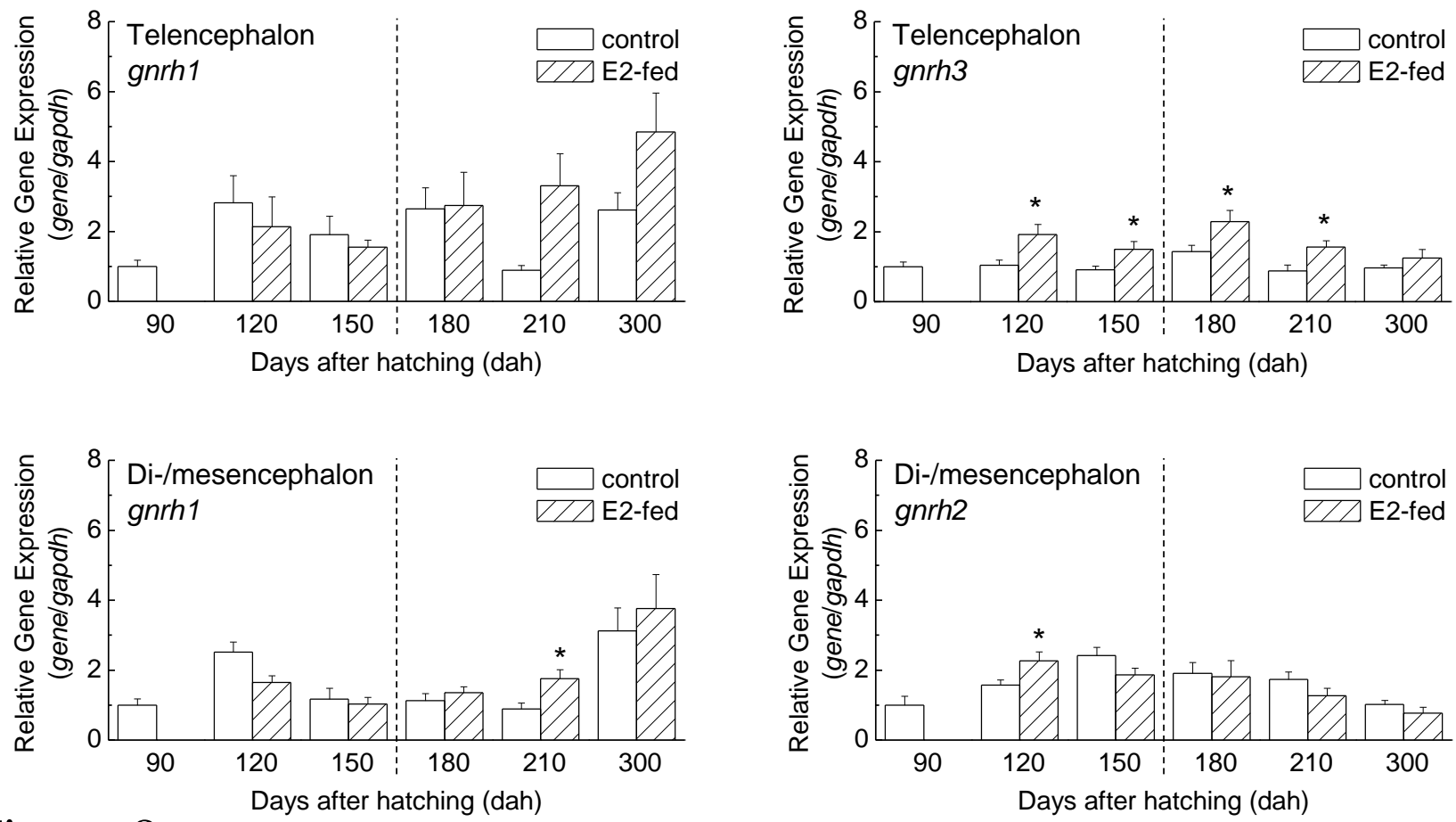

Figure 8 

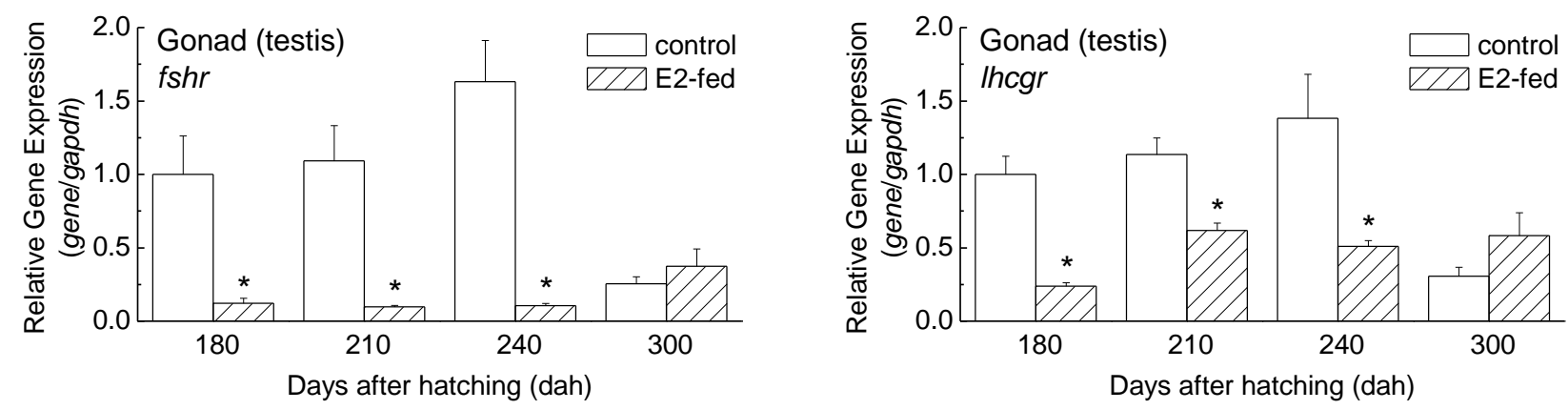

Figure 9 

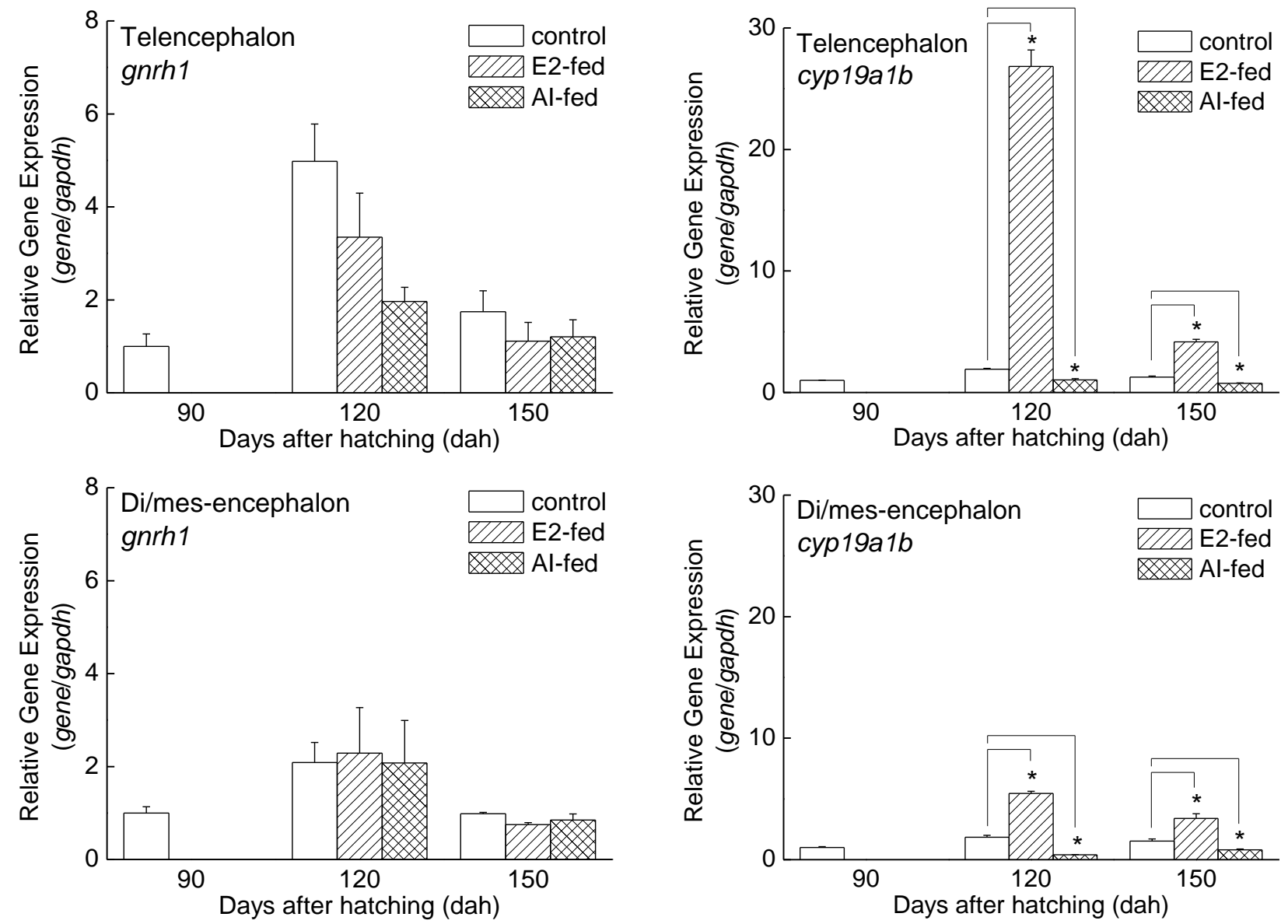

Figure 10 